\title{
Insulin Resistance as a Link between Amyloid-Beta and Tau Pathologies in Alzheimer's Disease
}

\author{
Roger J. Mullins ${ }^{1}$, Thomas C. Diehl ${ }^{1}$, Chee W. Chia ${ }^{2}$ and Dimitrios Kapogiannis ${ }^{1 *}$ \\ 'Laboratory of Neurosciences, Intramural Research Program, National Institute on Aging, National Institutes of Health \\ (NIA/NIH), Baltimore, MD, USA, ${ }^{2}$ Translational Gerontology Branch, Intramural Research Program, National Institute on \\ Aging, National Institutes of Health (NIA/NIH), Baltimore, MD, USA
}

Current hypotheses and theories regarding the pathogenesis of Alzheimer's disease (AD) heavily implicate brain insulin resistance (IR) as a key factor. Despite the many well-validated metrics for systemic IR, the absence of biomarkers for brain-specific IR represents a translational gap that has hindered its study in living humans. In our lab, we have been working to develop biomarkers that reflect the common mechanisms of brain $I R$ and $A D$ that may be used to follow their engagement by experimental treatments. We present two promising biomarkers for brain IR in AD: insulin cascade mediators probed in extracellular vesicles (EVs) enriched for neuronal origin, and two-dimensional magnetic resonance spectroscopy (MRS) measures of brain glucose. As further evidence for a fundamental link between brain IR and $A D$, we provide a novel analysis demonstrating the close spatial correlation between brain expression of genes implicated in IR (using Allen Human Brain Atlas data) and tau and beta-amyloid pathologies. We proceed

OPEN ACCESS

Edited by:

Rodrigo Orlando Kuljišs, University of Miami School of Medicine, USA

Reviewed by: Paula I. Moreira, University of Coimbra, Portugal Nobuyuki Kimura, National Center for Geriatrics and Gerontology, Japan

*Correspondence:

Dimitrios Kapogiannis kapogiannisd@mail.nih.gov

Received: 29 December 2016 Accepted: 11 April 2017 Published: 03 May 2017

Citation:

Mullins RJ, Diehl TC, Chia CW and Kapogiannis D (2017) Insulin

Resistance as a Link between Amyloid-Beta and Tau Pathologies in Alzheimer's Disease. Front. Aging Neurosci. 9:118. doi: 10.3389/fnagi.2017.00118 to propose the bold hypotheses that baseline differences in the metabolic reliance on glycolysis, and the expression of glucose transporters (GLUT) and insulin signaling genes determine the vulnerability of different brain regions to Tau and/or Amyloid beta $(A \beta)$ pathology, and that IR is a critical link between these two pathologies that define AD. Lastly, we provide an overview of ongoing clinical trials that target IR as an angle to treat $A D$, and suggest how biomarkers may be used to evaluate treatment efficacy and target engagement.

Keywords: Alzheimer's disease, insulin resistance, magnetic resonance spectroscopy, exosomes, IRS-1

Abbreviations: A $\beta$, Amyloid beta; AHBA, Allen human brain atlas; AD, Alzheimer's disease; APOE, apoliproprotein-E; APP, amyloid precursor protein; AKT, Protein Kinase B; BA, Brodmann's area; BMI, body-mass index; BBB, blood brain barrier; BDNF, brain derived neurotrophic factor; CAA, cerebral amyloid angiopathy; CSF, cerebrospinal fluid; cGMP, cyclic guanosine 3',5'-monophosphate; CMRGlc, cerebral metabolic rate for glucose; CRLB, Cramer-Rao Lower Bound; CSVD, cerebral small vessel disease; EV, extracellular vesicles; FDG-PET, Fluorodeoxyglucose Positron emission tomography; FFA, free fatty acids; FTO, fat mass and obesity-associated protein; GLP, glucagon like peptide; GLUT, glucose transporter; GSK, glycogen synthase kinase; HFD, high fat diet; HOMA-IR, homeostatic model assessment for insulin resistance; IDE, insulin degrading enzyme; IL6, interleukin 6; INS, insulin; INSR, insulin receptor; IR, insulin resistance; IRS, insulin receptor substrate; ISF, interstitial fluid; JNK, c-Jun N-terminal kinase; J-PRESS, 2D junctional point-resolved spectroscopy; MAP, microtubule associated proteins; MCI, mild cognitive impairment; MC4R, melanocortin-4 receptor; MNI, Montreal Neuroimaging Institute; mTOR, mammalian target of rapamycin; MRI, magnetic resonance imaging; MRS, magnetic resonance spectroscopy; NF-kB, nuclear factor kappa-light-chain-enhancer of activated B cells; NFT, neurofibrillary tangles; NO, nitric oxide; NP, neuritic plaques; PET, positron emission tomography; PI3K, phosphoinositide 3-kinase; $\mathrm{PiB}$, Pittsburgh compound B; PP2A, protein phosphatase 2; PKB/Akt, protein kinase B; RAGE, receptor for advanced glycation end products; S6K1, ribosomal protein S6 kinase beta-1; TNF, tumor necrosis factor; VCID, vascular contribution of cognitive impairment and dementia. 


\section{THE MOLECULAR BASIS OF INSULIN RESISTANCE}

The binding of insulin to the insulin receptor leads to the recruitment and phosphorylation of the insulin receptor substrates 1 and 2 (IRS1 and 2; Draznin, 2006). These molecules represent the first node in the insulin signaling cascade, with further downstream nodes being phosphoinositide 3-kinase $(\mathrm{PI} 3 \mathrm{~K})$ and protein kinase $\mathrm{B}(\mathrm{PKB} / \mathrm{Akt})$, which in turn affect master regulatory switches of cell metabolism, cell survival, growth and differentiation, such as the mammalian target of rapamycin (mTOR), and glycogen synthase kinase 3 (GSK3; Pessin and Saltiel, 2000; Sarbassov et al., 2005; Tzatsos, 2009; Zhang and Liu, 2014).

Persistent activation of the insulin receptor results in excessive phosphorylation of Ser and Thr residues on IRSs (Czech et al., 1988; Singh, 1993; Tanti et al., 1994). This aberrant phosphorylation of IRS results in reduced insulin receptor binding sensitivity and translocation of the active portion of IRS from the membrane to the cytosol, and is one of the main molecular underpinnings of insulin resistance (IR; Aguirre et al., 2002; Boura-Halfon and Zick, 2009; Copps and White, 2012; Ryu et al., 2014). Moreover, these mechanisms have the potential for establishing pathogenic feed-forward loops that inhibit normal insulin signaling, as $\mathrm{mTOR}$, ribosomal protein S6 kinase beta-1 (S6K1), and GSK3- $\beta$ induce hyperphosphorylation at various Ser residues (S632, S302/S522 and S337, respectively; EldarFinkelman and Krebs, 1997; Copps and White, 2012).

A key physiological action of insulin is to increase glucose uptake into cells (Leney and Tavaré, 2009) by inducing translocation of various insulin-dependent glucose transporters (GLUTs) to the plasma membrane. GLUT-3 is the primary brain GLUT and is mainly expressed in axons and dendrites, but GLUT-1 and 4 are also expressed in the brain (Maher et al., 1991; Simpson et al., 2008). The uniquely low Michaelis-Menten constant of GLUT-3 allows for continuous transport of glucose into neurons even under low extracellular concentrations, thereby providing a consistent energy source (Duelli and Kuschinsky, 2001). Different isoforms of GLUT-1 mediate glucose uptake by astrocytes as well as the endothelial cells of the blood brain barrier (BBB). Interestingly, neurons in areas vulnerable to Alzheimer's disease ( $\mathrm{AD}$; e.g., basal forebrain cholinergic neurons) show partial GLUT-4 dependence, which may help explain their vulnerability in low energy conditions and AD (Morgello et al., 1995; Apelt et al., 1999; Duelli and Kuschinsky, 2001). In systemic and organ-specific IR states, the ability of insulin to stimulate glucose uptake via GLUT transporters is impaired, requiring higher than normal concentrations of extracellular insulin to maintain normal glucose uptake to match cellular metabolic needs (Lebovitz, 2001).

\section{BRAIN INSULIN AND THE BBB}

While there is evidence that insulin is produced de novo in different brain regions, the general consensus remains that a majority of the insulin in the brain arrives from the periphery through the BBB (Pardridge et al., 1985; Kullmann et al., 2015), where it is concentrated to levels $50 \times$ higher than in circulating plasma independently of peripheral hormonal states (Havrankova et al., 1979; Banks et al., 2012; Blázquez et al., 2014). Peripherally produced insulin crosses the BBB via a saturable transport system, with partial saturation occurring at standard euglycemic levels (Woods and Porte, 1977; Banks, 2004). Peripheral insulin can enter the brain interstitial fluid (ISF) either directly through the $\mathrm{BBB}$ or via cerebrospinal fluid (CSF), but the relative contributions of each are not yet known (Genders et al., 2013). The levels of CSF glucose and insulin only partially reflect blood levels, suggesting their differential regulation in this compartment (Woods and Porte, 1977). In humans, the transfer of blood insulin into the CSF has been confirmed during intravenous injections of insulin (Wallum et al., 1987). Interestingly, in obesity the CSF/plasma insulin ratio is decreased, a finding that should be taken within broader context, as the CSF/plasma ratios for leptin and adiponectin are also decreased (Caro et al., 1996; Kos et al., 2007).

The $\mathrm{BBB}$ is a dynamic structure that homeostatically regulates the uptake and release rates for a variety of hormones, chemicals, and proteins (Daneman, 2012). Accordingly, fluctuations in plasma levels of both glucose and insulin affect their uptake by the BBB (Prasad et al., 2014). This uptake is carried out by the GLUT-1 and GLUT-3 transporters embedded within the $\mathrm{BBB}$ endothelium, providing the ability to respond to variable energy demands (Leybaert et al., 2007). This dynamic is demonstrated in a study that found glucose transport across the BBB increased with luminal expression of GLUT-1, whereas higher abluminal GLUT-1 expression was accompanied by decreased glucose transport (Cornford and Hyman, 2005). Insulin receptor expression is also reduced in the $\mathrm{BBB}$ when there is prolonged peripheral hyperinsulemia (Schwartz et al., 1990). The rate of insulin transport across the BBB is also slowed by obesity and aging. Obesity decreases the transport of insulin across the $\mathrm{BBB}$, and this deficit can be reversed by starvation and caloric restriction (Urayama and Banks, 2008). Aging leads to an overall decrease in the number of insulin receptors at the BBB (Moreira et al., 2009). Insulin transport is diminished as a consequence, with CSF insulin levels being lower in both obese and older individuals (Heni et al., 2015). Insulin levels in the brain tissue of older individuals are also lower (Frölich et al., 1998). Additionally, decreased CSF levels of insulin correlate with poorer cognitive performance in patients with diabetes or $\mathrm{AD}$ (Moloney et al., 2010; Duarte et al., 2012).

Evidence also exists that insulin can be produced de novo in brain regions with many pyramidal cells, such as the hippocampus, prefrontal cortex, olfactory bulb and entorhinal cortex (Havrankova et al., 1978; Heidenreich and Gilmore, 1985; Marks et al., 1991; Devaskar et al., 1994; Mehran et al., 2012). While the significance of this evidence is still debated, recent studies show that functional insulin signaling components in forebrain regions may exert a neuroprotective role in areas responsible for various functions of memory (McNay and Recknagel, 2011; De Felice et al., 2014). Downstream elements in the signaling pathway known as the "PI3K route" have been 
shown to both promote neuronal cell survival and facilitate synaptic plasticity, providing a link between IR and AD (van der Heide et al., 2006).

\section{BRAIN INSULIN RESISTANCE}

A variety of genetic, developmental, and metabolic factors underlie brain IR. Polymorphisms in the Fat Mass and ObesityAssociated Protein (FTO) gene, involving introns 1 and 2 that are highly expressed in the brain, exhibit strong effects on brain IR (Reitz et al., 2012). Carriers of the at-risk FTO-AA allele who are also carriers of an apolipoprotein-E (APOE) $\varepsilon 4$ allele have a significantly increased risk for $\mathrm{AD}$ and dementia (Keller et al., 2011). Additionally, a single nucleotide polymorphism near the Melanocortin-4 Receptor (MC4R) gene, a gene expressed in brain regions that regulate systemic metabolism such as the hypothalamus (Shen et al., 2013), has been linked to increased brain IR (Tschritter et al., 2011). Moreover, maternal glucose and insulin sensitivity correlate with fetal brain responses to fluctuations in circulating glucose, suggesting a prenatal predisposition to brain IR (Linder et al., 2014). Increased circulating free fatty acids may also play a role in establishing brain IR. High fat diet (HFD) leads to rapid release of pro-inflammatory factors at the hypothalamus, and triggers the c-Jun N-terminal kinase (JNK) pathway to increase activation of the leptin and insulin signaling inhibitor nuclear factor kappalight-chain-enhancer of activated B cells (NF-kB; Nakano, 2004; Sears and Perry, 2015).

Dysfunctional phosphorylation of IRS-1 has been extensively linked with brain IR, similar to other tissues. Total levels of insulin signaling proteins in the aforementioned "PI3K route" are not significantly different in the brains of $\mathrm{AD}$ patients vs. cognitively normal $(\mathrm{CN})$ controls, suggesting that the phosphorylated active levels of these molecules are more relevant to IR and $\mathrm{AD}$ pathogenesis as opposed to total levels (Talbot et al., 2012). Studies in human hippocampal tissue have shown that phosphorylation mediated by factors such as mTOR and GSK-3 $\beta$, coupled with feed-forward inhibition from the JNK pathway, leads to specific increased phosphorylation on multiple Ser residues of IRS-1 (specifically, S312, S616 and S636; Boura-Halfon and Zick, 2009; Fröjdö et al., 2009; Talbot et al., 2012). However, conflicting evidence exists showing that S307 phosphorylation in mice (human S312) may in fact increase insulin sensitivity and improve insulin signaling (Copps et al., 2010).

\section{VASCULAR EFFECTS OF BRAIN INSULIN RESISTANCE}

Vascular function is tightly coupled to insulin signaling, and central to this relationship is endothelial dysfunction, which manifests through deficient vasodilation and improper vasoconstriction throughout the body in the setting of IR (Hsueh et al., 2004; Quiñones et al., 2004; Cersosimo and DeFronzo, 2006). The vasodilator effects of insulin are mediated by the PI3K signaling pathway, which leads to nitric oxide
(NO) production in endothelial cells which elevates cyclic guanosine $3^{\prime}, 5^{\prime}$-monophosphate (cGMP) in vascular smooth muscle; insulin vasoconstrictor effects are mediated through endothelin-1 (Muniyappa and Quon, 2007; Muniyappa and Sowers, 2013). Insulin signaling causes a dose-dependent increase in NO production (Zeng and Quon, 1996), whereas impaired PI3K signaling decreases $\mathrm{NO}$ and cGMP, leading to decreased vasodilation (Francis et al., 2010). NO also inhibits platelet aggregation, monocyte adhesion, and thrombosis, all of which damage the vessel wall (Celermajer, 1997). Microvascular disruption leads to superoxide production, which, among other events, leads to a rise in advanced glycation end products. Pathological activation of the receptor for these advanced glycation end products (RAGE) increases oxidative stress, exacerbating vascular inflammation, thrombosis, and vascular damage (Kook et al., 2012). Impaired endothelial cell-mediated vasodilation may also be caused by excess free fatty acids (FFAs) traveling in the blood stream (Steinberg et al., 1997). FFA's are often elevated in diabetic patients, and through the action of the inhibitor of nuclear factor kappa $B$ kinase subunit beta (IKKB, which modulates NF-kB) inhibit the production of NO, decreasing vasodilation, deteriorating cardiovascular function, and exacerbating the insulin resistant state (Ginsberg, 2000; Kim et al., 2005).

Significant vascular pathology is frequently seen in older individuals with dementia. In fact, until the significance of neuritic plaques (NP) and neurofibrillary tangles (NFT) was unequivocally demonstrated, the prevailing view was that vascular pathology is primarily responsible for the cognitive deficits in AD (Kling et al., 2013). Vascular dementia is thought to be the second most common form of dementia after $\mathrm{AD}$ (Jellinger, 2007), whereas mixed pathology dementia is being increasingly reported in the literature, with more than half of all dementia cases being attributed to dual pathology (Langa et al., 2004; Schneider et al., 2007; Battistin and Cagnin, 2010). A variety of small and large vessel cerebrovascular disease pathologies have been described, including silent infarcts, leukoaraiosis (seen on magnetic resonance imaging (MRI) as white matter hyperintensities), cerebral amyloid angiopathy (CAA), microaneurysms, and small and large vessel ischemic/hemorrhagic stroke (Breteler, 2000; Gorelick et al., 2011; Attems and Jellinger, 2014; Corriveau et al., 2016). Recently, the term "vascular contribution of cognitive impairment and dementia" (VCID) has been coined to capture this heterogeneity.

There is emerging evidence showing that IR and diabetes have significant implications in VCID. It is well known that cerebral blood flow is decreased in diabetic patients (Jellinger, 2007). Cerebral small vessel disease (CSVD) is the cause of approximately $20 \%$ of strokes and the underlying etiology for many of the other pathologies previously mentioned (Lammie et al., 1997; Cai et al., 2015). Importantly, CSVD is aggravated by diabetes. Specifically, pathological hallmarks such as incident, small and large lacunes, and white matter hyperintensities seem to correlate with progression of IR (Dearborn et al., 2015). Diabetes also increases the risk for large vessel disease, and is present in approximately 30\% of strokes 
(Karapanayiotides et al., 2004). A study showed that for each standard deviation increase in homeostatic model assessment for insulin resistance (HOMA-IR) and body-mass index (BMI), there was an increase in incident large lacunes. Moreover, higher IR score correlated with the increase in prevalence of both small and large lacunes (Dearborn et al., 2015). Increased HOMA-IR scores are associated with higher risk of ischemic stroke even among non-diabetics (Rundek et al., 2010). Interestingly, IR has been reported in almost half of non-diabetics who presented with a transient ischemic attack (Kernan et al., 2003).

\section{THE INTERPLAY OF INSULIN RESISTANCE AND A $\beta$ PATHOLOGY}

Several epidemiological studies have shown that the systemic IR state of type 2 diabetes is a major risk factor for age-related cognitive decline, dementia, $\mathrm{AD}$, and progression from mild cognitive impairment (MCI) to AD (Ott et al., 1999; Arvanitakis et al., 2004; Li et al., 2016). Besides the aforementioned vascular contributions, several lines of evidence suggest that brain IR directly promotes the development of classic AD beta-amyloid $(\mathrm{A} \beta$ ) and tau pathologies (Steen et al., 2005; de la Monte, 2012). Brain IR may also exacerbate pre-existing $\mathrm{AD}$ pathology by this same mechanism and is known to be associated with cognitive decline independently of AD pathology (Talbot et al., 2012; Umegaki, 2013).

A $\beta$ refers to several peptides between 39-43 amino acids in length that are formed by the sequential $\beta$ and $\gamma$ secretase cleavage of the amyloid precursor protein (APP); a large transmembrane protein with an unknown physiologic role. Aberrant oligomerization of certain $\mathrm{A} \beta$ peptides (such as $\mathrm{A} \beta 42$ ) and formation of extracellular plaques with $A \beta$ fibrils at their center in equilibrium with soluble oligomers are histopathological hallmarks of AD (Hardy and Selkoe, 2002; Blennow, 2004; Pearson and Peers, 2006; Greenwald and Riek, 2010). It has been shown that the distribution of regional glucose metabolism via glycolysis in normal young adults correlates spatially with $\mathrm{A} \beta$ deposition in individuals with $\mathrm{AD}$, suggesting a pathogenic link between glycolysis in earlier life and eventual development of A $\beta$ pathology (Phelps and Barrio, 2010; Vaishnavi et al., 2010; Vlassenko et al., 2010). Moreover, an important study found that regional lactate production is closely linked to interstitial $A \beta$ levels, establishing an additional link between glycolytic energy metabolism and a key pathogenic protein in AD (Bero et al., 2011). Lactate is produced by astrocytes as a product of glycolysis and can be used as an alternate neuronal energy substrate in conditions that do not favor aerobic metabolism (Magistretti and Pellerin, 1999). More recently, elevated lactate in transgenic $\mathrm{AD}$ mice compared to wild type mice was seen in vivo and in association with memory deficits (Harris et al., 2016). A putative interplay between increased reliance on glycolysis, increased production of lactate and ensuing increased extracellular $A \beta$ has the potential of establishing a feed-forward loop that perpetuates and aggravates $\mathrm{A} \beta$ pathology in $\mathrm{AD}$.

It has been shown that insulin promotes brain $\mathrm{A} \beta$ clearance, preventing its extracellular accumulation and plaque formation
(Watson et al., 2003). Conversely, IR promotes the formation of $\mathrm{A} \beta$ fibrils by inducing GM1 ganglioside clustering in presynaptic membranes (Yamamoto et al., 2012). A $\beta$ oligomers increase activation of the JNK pathway, leading to increased IRS-1 pS616 (as well as Tau pS422; Yoon et al., 2012). Collectively, these data suggest a feed-forward loop where $A \beta$ oligomers aggravate brain IR, which in turn decreases $A \beta$ clearance and increases the propensity for $A \beta$ oligomerization. Moreover, a recent study showed that $\mathrm{A} \beta$ oligomers acting at the hypothalamus (through a mechanism involving NF- $\mathrm{B}$ signaling) trigger peripheral IR, potentially establishing a second feed-forward loop between AD pathology, peripheral IR and brain IR (Clarke et al., 2015).

$\mathrm{A} \beta$ can be degraded by a variety of peptidases, such as the insulin degrading enzyme (IDE), neprilysin and angiotensin converting enzyme, as well as multiple serine proteases (plasmin, urokinase-type and tissue-type plasminogen activators; Wang et al., 2006; Saido and Leissring, 2012). Because of IDE's ability to degrade insulin as well as $\mathrm{A} \beta 42$, it is thought to be a link connecting hyperinsulemia, IR, and AD (Authier et al., 1996; Qiu and Folstein, 2006). Although IDE is thought to only cleave monomeric A $\beta$ (Hulse et al., 2009; Saido and Leissring, 2012), a decrease in its action could shift the equilibrium towards $A \beta$ oligomerization. In mice, IR leads to increased brain amyloidosis through an increase in gamma-secretase activity, as well as decreased IDE (Ho et al., 2004; Starks et al., 2015). Furthermore, in $\mathrm{AD}$ patients with the $\mathrm{APOE} \varepsilon 4$ allele, IDE expression in areas such as the hippocampus is greatly reduced (Edland, 2004).

\section{THE INTERPLAY OF INSULIN RESISTANCE AND TAU PATHOLOGY}

Tau is a member of a large group of proteins known as microtubule associated proteins (MAPs). In its native conformation, tau is a soluble and unfolded protein involved in microtubule stabilization and axonal outgrowth. However, hyperphosphorylated tau tends to aggregate and these tau aggregates are seen in various neurodegenerative diseases. In $\mathrm{AD}$, tau forms intracellular NFTs, which alongside extracellular A $\beta$ NPs constitute the two main histopathological hallmarks of the disease (Brandt and Leschik, 2004).

Several studies have implicated IR in tau aggregation, which largely depends on its phosphorylation state, which is in turn determined by the balance between various kinase and phosphatase activities. Intravenous insulin administration exerts a biphasic effect on tau phosphorylation. Short-term administration of insulin to human neuroblastoma cells or rat primary cortical neurons leads to rapid hyperphosphorylation of tau at several Ser/Thr residues, whereas prolonged exposure results in decreased phosphorylation (Lesort et al., 1999; Lesort and Johnson, 2000). This increase and subsequent decrease is mirrored by the activity of GSK-3 $\beta$, widely considered to be the primary kinase responsible for the phosphorylation of Tau in vivo and modulated by insulin via the $\mathrm{PKB} / \mathrm{Akt}$ pathway (Welsh and Proud, 1993; Hong and Lee, 1997; Planel et al., 
2002; Llorens-Martín et al., 2014). A recent study suggests that a shift in APP processing from the $\alpha$-secretase pathway to the $\beta$ - and $\gamma$-secretase pro-amyloidogenic pathway increases GSK$3 \beta$-mediated tau phosphorylation, establishing a connection between the two core pathologies in AD (Deng et al., 2015), with brain IR aggravating them both. Upstream of GSK-3 $\beta$, $\mathrm{PKB} /$ Akt itself also functions as a Ser/Thr kinase and has the ability to phosphorylate Tau directly, at least in vitro (KsiezakReding et al., 2003; Zhou et al., 2009). Conversely, inhibiting the Ser/Thr phosphatases responsible for tau dephosphorylation can also increase the overall phosphorylation of tau. Protein phosphatase 2 (PP2A) is the primary tau phosphatase implicated in $\mathrm{AD}$ and is suppressed by insulin administration in both human and animal studies (Gong et al., 1995; Kins et al., 2001; Vogelsberg-Ragaglia et al., 2001; Clodfelder-Miller et al., 2006; Papon et al., 2013). Ob/ob transgenic mice are obese with high blood sugar and insulin levels, low levels of IRS-1 and 2, behavioral deficits, and tau hyperphosphorylation (Kerouz et al., 1997; Asakawa et al., 2003; Kim et al., 2013; Porter et al., 2013). Db/db mice also reliably display a phenotype of obesity, increased tau phosphorylation and IR accompanied by profound behavioral deficits in learning and memory (Kim et al., 2009; Sharma et al., 2010; Dinel et al., 2011). The combined effects of diminished insulin pathway activity in increasing tau phosphorylation and decreasing tau de-phosphorylation may broadly explain the increased tendency for tau aggregation with brain IR. Moreover, in the brains of $\mathrm{AD}$ patients, increased cytosolic levels of IRS-1 pS312 and pS616 correlate with the presence of NFTs, whereas, in CN controls, IRS-1 pS312 is restricted to nuclear regions of the cell. This finding suggests that IRS-1 phospho-species may have actions promoting tau pathology in $\mathrm{AD}$ beyond their role in the development of brain IR (Moloney et al., 2010).

Besides its role in the development of $A \beta$ and tau pathology, brain IR can also directly affect synaptic function and cognition. For instance, in mice, down-regulation of insulin receptors in the hippocampus impairs hippocampal long-term potentiation and spatial learning (Grillo et al., 2015), whereas their down-regulation in the hypothalamus results in decreased hippocampal brain derived neurotrophic factor (BDNF; Grillo et al., 2011). Neurodegeneration, tau hyperphosphorylation and increased $\mathrm{A} \beta$ burden have also been reliably evoked in transgenic mice as a consequence of HFD, an intervention that reliably causes IR (Julien et al., 2010; Hiltunen et al., 2012). Both IR and oxidative stress independently lead to the accumulation of $\mathrm{A} \beta$ and phosphorylated tau (Chen et al., 2003; Grünblatt et al., 2007). Oxidative stress, an imbalanced biochemical state wherein the cell produces more reactive oxygen species than its antioxidant activity can withstand, also occurs as a result of metabolic syndrome and obesity (Davì et al., 2002).

\section{SPATIAL CORRELATION OF IR-RELATED GENES AND AD PATHOLOGY}

The emergence of "big data" in neuroscience, particularly from gene expression microarrays, brought with it promising bioinformatics methods designed to take advantage of its sheer volume. The prominence of these new "neuroinformatics" methods in no way implies that older, well established data should be left behind. The synthesis of old and new data can be invaluable for exploratory studies and hypothesis generation. For example, when data of different modalities are distributed spatially over the entire brain, as is often the case for MRI data, tissue histology, positron emission tomography (PET), etc., this opens the possibility of comparison by pairwise spatial correlation. Often referred to as "guilt by association", (Stuart et al., 2003), the concept behind this method is that shared spatial patterns of gene expression and other data (e.g., MRI features) also suggests participation in a shared function (Hawrylycz et al., 2011). This type of analysis essentially examines genotype-phenotype associations across small parcels of the brain rather than across human subjects. This approach may be suitable for diseases where there is a concrete spatial pattern of vulnerability across brain areas and for testing hypotheses that associate preferential vulnerability and differential gene expression.

To provide further evidence for the relationship between brain IR and the propensity to develop plaques and tangles., we examined how the spatial distributions of $A \beta$-containing NPs and hyperphosphorylated tau-containing NFTs relate to the spatial expression of genes implicated in brain IR. We hypothesized that areas that show lower levels of GLUT and insulin signaling genes are less able to adapt to energetic challenges and are more vulnerable to AD pathology (Mamelak, 2012). We derived values of double-blinded rater assessments of the density of plaques and tangles from a seminal histological study on their topography in AD (Arnold et al., 1991) and converted them into 3D spatial map in Montreal Neuroimaging Institute (MNI) space (Figure 1). We then derived microarray expression levels $\left(\log ^{2}\right)$ for IR-related genes of interest (GSK3B, IRS1, INS, INSR, GLUT1, GLUT3, GLUT4, AKT1, AKT2, AKT3, IL6, TNF, FTO, MC4R and mTOR) from the Allen Human Brain Atlas $\left(\mathrm{AHBA}^{1}\right)$, using the single probe with the highest overall expression when multiple probes exist. Like the NP/NFT maps, the AHBA provides numerous ( $\sim 500$ per specimen) microarray samples spatially distributed over six healthy "normal" control brain specimens (Hawrylycz et al., 2012; Sunkin et al., 2013). The expression levels for brain samples located within a given Brodmann area were averaged to make a new 3D map for each gene probe registered into MNI space and broken down by Brodmann areas. With these two spatially coregistered maps of histopathological and AHBA gene expression data established, a custom MATLAB (The Mathworks, Inc., Natick, MA, USA) script was used to perform pairwise Pearson correlations between NP or NFT densities vs. gene expression values for each Brodmann area (Figure 2).

Given that the AHBA brain specimens belonged to healthy individuals, positive correlations indicate regions where the normal expression of these genes is spatially similar to the Tau and/or $\mathrm{A} \beta$ pathologies seen in $\mathrm{AD}$. In other words, these genes have higher expression in regions with high density of plaques or

\footnotetext{
${ }^{1}$ http://human.brain-map.org/static/download
} 


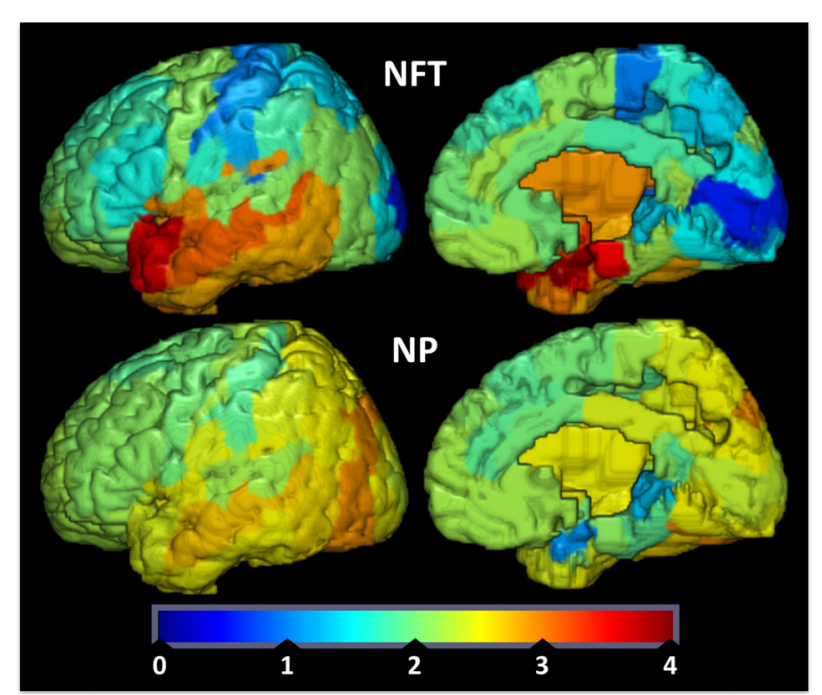

FIGURE 1 | Tau tangle (neurofibrillary tangles (NFT), upper row) and amyloid-beta plaque (neuritic plaques (NP), bottom row) values were redrawn from data originally presented in Arnold et al. (1991) and superimposed on Brodmann maps (BA 1-48) from MRIcroGL version 1.150909. NFT and NP values are double-blinded rater assessments of tangle or plaque density. Color map and bar ("jet") is red high, blue low.

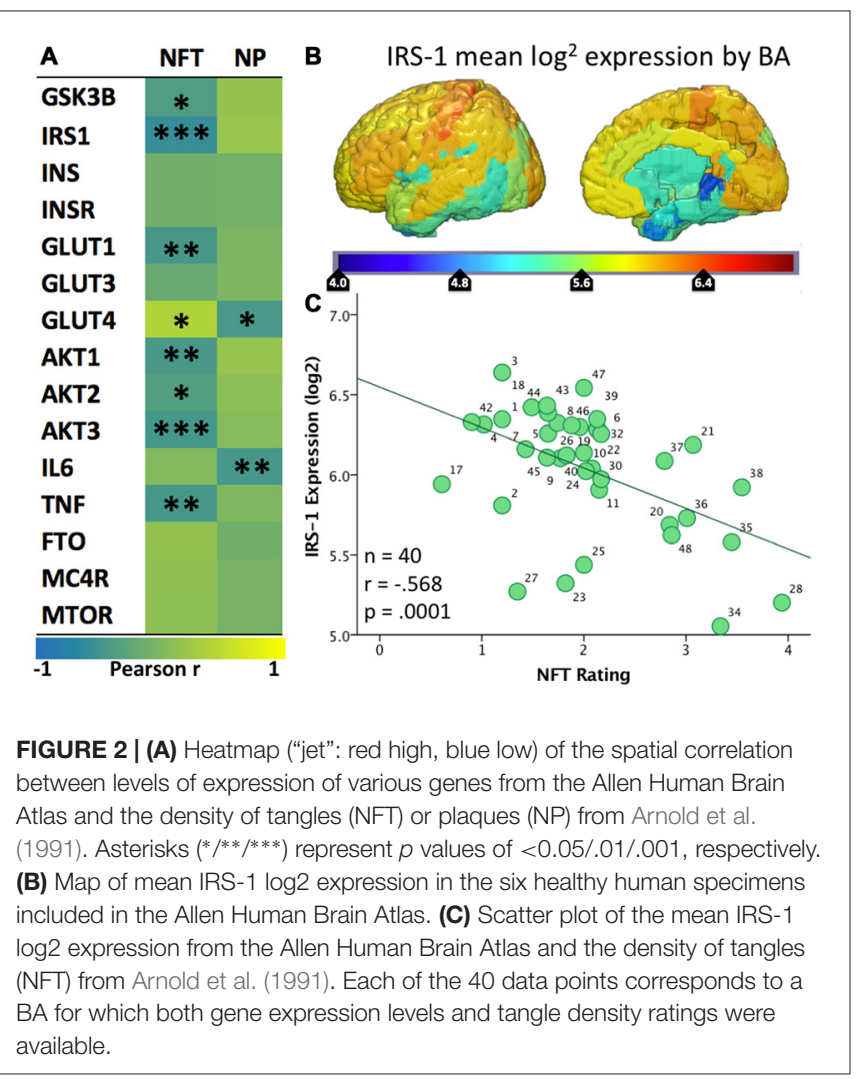

tangles in $\mathrm{AD}$ and lower expression in less vulnerable regions. $\mathrm{A}$ strong and significant positive association was seen between NFT density and expression of GLUT4 $(r=0.39, p=0.018)$. Negative correlations suggest the reverse; wherein normal expression of these genes is low in the areas most vulnerable to $\mathrm{AD}$ plaques and tangles and high in less vulnerable areas. Significant negative correlations with NFTs were found for multiple insulin signaling genes, including IRS1 $(-0.57, p<0.001)$, AKT1 $(r=-0.42$, $p=0.007), \operatorname{AKT} 2(r=-0.33, p=0.033)$, AKT3 $(r=-0.45$, $p=0.003)$, GSK3B $(r=-0.36, p=0.019)$, and GLUT1 $(r=-0.43$, $p=0.005)$. The NP map correlated negatively with GLUT4 $(r=-0.42, p=0.01)$.

IRS-1 regulates insulin signaling upstream of AKT and GSK3B, and prior studies have noted a decreased overall level of IRS-1 and related pathway molecule expression in $\mathrm{AD}$ neurons (Steen et al., 2005; Moloney et al., 2010). The observed negative spatial correlation with NFTs suggests that regions that normally show low levels of expression of IRS-1 are more likely to develop tau pathology in the setting of AD. We recently published a study showing that levels of pSer312-IRS1 in extracellular vesicles (EVs) enriched for neuronal origin are associated with brain atrophy in a regional pattern that corresponds to IRS1 expression (Mullins et al., 2017). Given that NFTs are known to be closely associated with atrophy, our findings collectively tie together IRS1 expression and post-translational phosphorylation, NFT pathology and atrophy. Regarding GLUTs, it has already been reported that neurons in areas vulnerable to $A D$ show partial GLUT4 dependence, and it has been suggested that this may partially explain their vulnerability (Morgello et al., 1995; Apelt et al., 1999; Duelli and Kuschinsky, 2001). Moreover, we have noted that different isoforms of GLUT1 are expressed by astrocytes and endothelial cells, but unfortunately it is unclear to what extent GLUT1 expression in AHBA samples represents astrocytes vs. endothelial cells. Nevertheless, the present analysis demonstrates that normal regional expression of GLUT4 is positively associated with NFT density in AD, while GLUT1 is negatively associated. In other words, areas that normally have few GLUT1s and many GLUT4s show the greatest propensity for developing tau pathology in AD; see Figure $\mathbf{3}$ for summary and select detailed scatterplots from these findings. For the IR genes of interest, there are more (8 vs. 2 ) correlations with the NFTs than the NPs map.

\section{IR AS A LINK BETWEEN A $\beta$ AND TAU PATHOLOGIES IN AD}

One of the main enduring mysteries in $\mathrm{AD}$ is the different distribution of NFTs and NPs in the disease (Arnold et al., 1991). The various lines of evidence reviewed above and the novel analysis presented enable us to formulate a bold new hypothesis that considers IR as an important link between $\mathrm{A} \beta$ and Tau pathologies in $\mathrm{AD}$ and the main determinant of their regional distribution. Baseline differences in the reliance in glycolysis to generate energy, the expression of GLUT and insulin signaling genes determine the vulnerability of different brain regions to Tau and/or $A \beta$ pathology. As mentioned already, extensive temporo-parietal areas of the brain show significant metabolic reliance on glycolysis (Phelps and Barrio, 2010; Vaishnavi et al., 2010; Vlassenko et al., 2010), which generates lactate. High lactate 


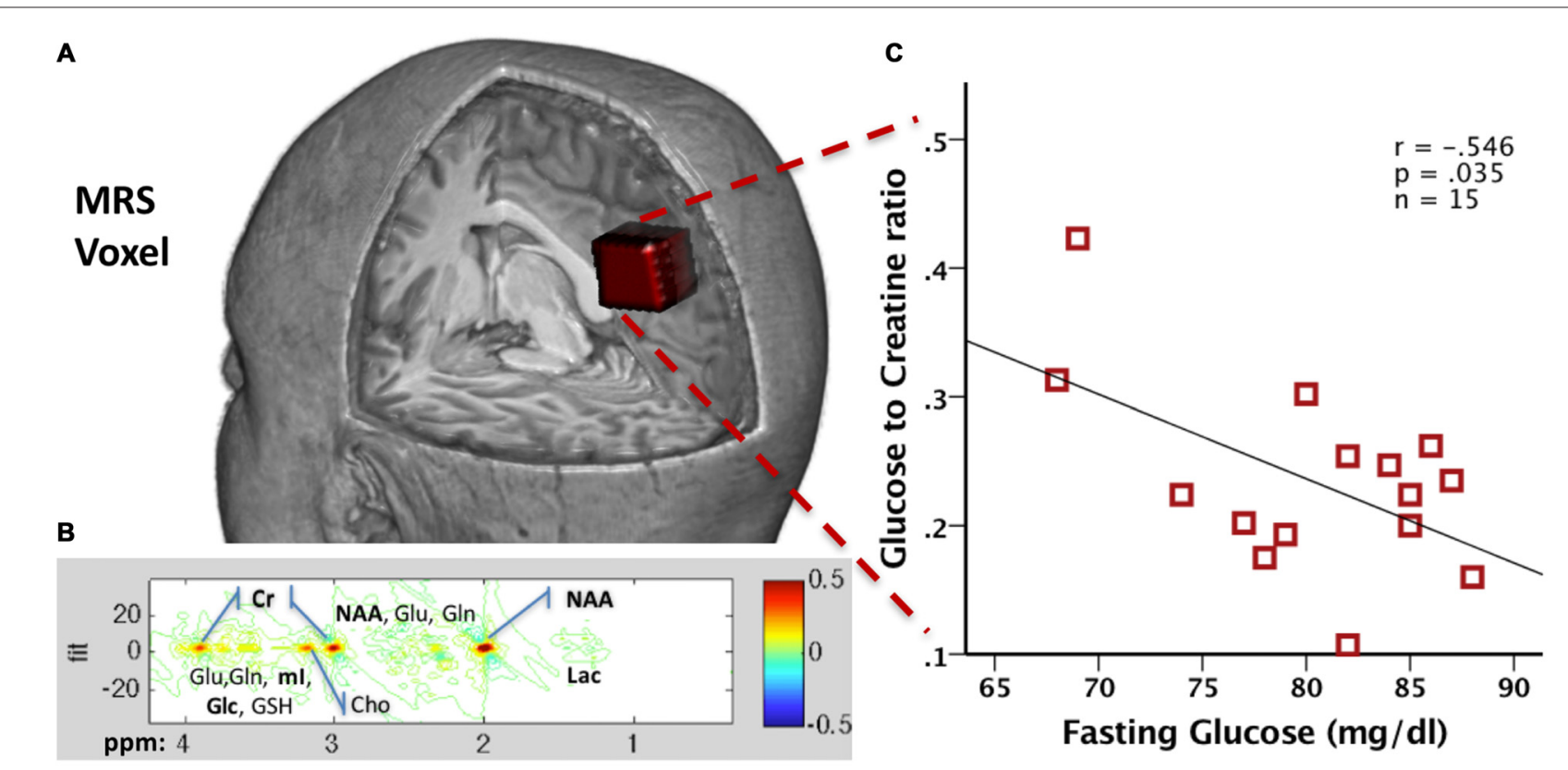

FIGURE 3 | (A) Precuneal voxel placement for the junctional point-resolved spectroscopy (J-PRESS) acquisition is shown in red $\left(25 \times 18 \times 20 \mathrm{~mm}^{3}\right)$ within a 3D brain cutaway image (figure created in MRIcroGL version 1.150909). (B) Sample 2D J-PRESS spectral fitting from a representative 48-year-old male cognitively normal (CN) participant. (C) Scatter plot of the correlation between the Glc/Cr and fasting Glucose values in 15 healthy male participants (red squares).

Baseline gene expression differences Differential vulnerability

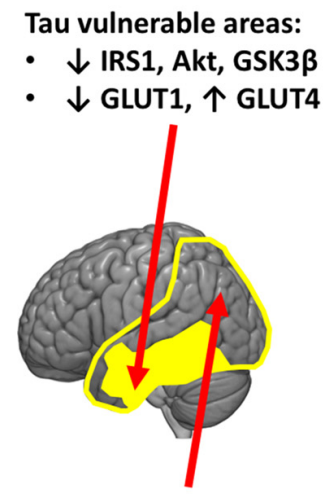

$A \beta$ vulnerable areas:

- $\downarrow$ GLUT4

- Anaerobic glycolysis

- $\uparrow$ interstitial lactate
pSer $\uparrow \&$ pTyr $\downarrow$ IRS1

$\downarrow$ downstream insulin signaling
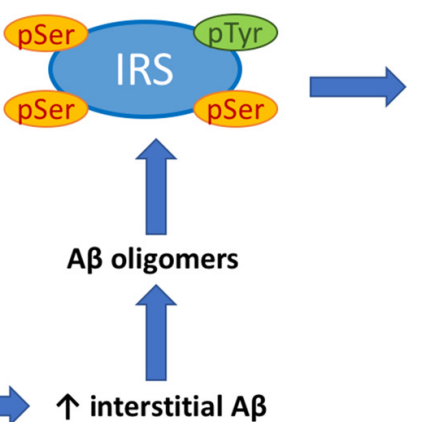

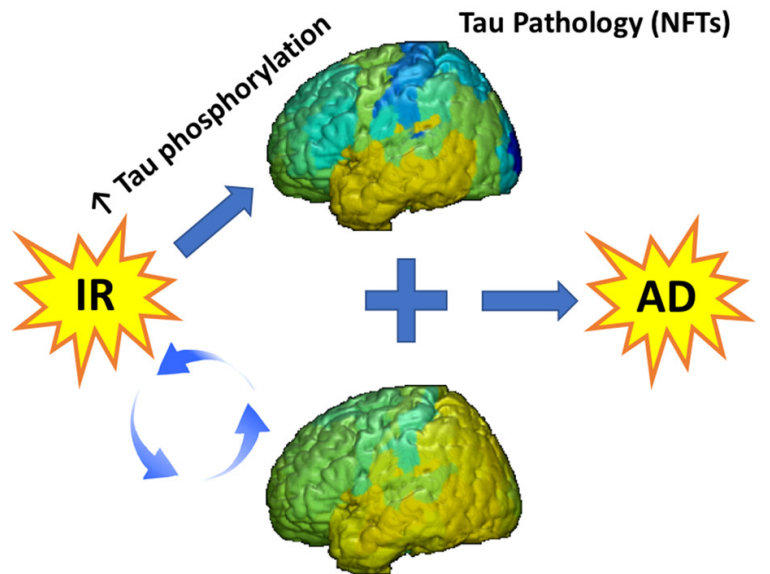

$A \beta$ Pathology (NPs)

FIGURE 4 | Graphical abstract. Baseline differences in the expression of glucose transporters (GLUT) and insulin signaling genes determine the vulnerability of different brain regions to Tau and/or A $\beta$ pathology. Extensive temporo-parietal areas of the brain show significant metabolic reliance on glycolysis, which generates lactate. High lactate is associated with high interstitial A $\beta$, which assembles into A $\beta$ oligomers. These A oligomers promote Ser phosphorylation of IRS-1, impeding downstream insulin signaling and leading to brain IR. A feed-forward loop is established between IR and A $\beta$ pathology leading to progressive A $\beta$ deposition in NP. Chronic IR promotes tau hyperphosphorylation and this effect is more pronounced in regions that show low expression of insulin signaling proteins (IRS-1, Akt, etc.) at baseline. As a result, hyperphosphorylated tau leads to the development of NFT in a different and more restricted regional pattern than A $\beta$. The sum of these three inter related pathologies (IR, $A \beta$, Tau) produces Alzheimer's disease.

is associated with high interstitial $A \beta$, which assembles into $A \beta$ oligomers. These A $\beta$ oligomers promote Ser phosphorylation of IRS-1, impeding downstream insulin signaling and leading to brain IR. A feed-forward loop is established between IR and $A \beta$ pathology leading to progressive $A \beta$ deposition in NPs across extensive parts of the brain. Chronic IR promotes tau 
hyperphosphorylation and this effect is more pronounced in regions that show low expression of insulin signaling proteins (IRS-1, Akt, etc.) at baseline (earlier adult life). As a result, hyperphosphorylated tau leads to the development of NFTs in a different and more restricted regional pattern than $A \beta$. The sum of these three inter related pathologies (IR, $A \beta$, Tau) produces Alzheimer's disease (AD).

This hypothetical paradigm is based on correlational studies but its predictions are testable (and falsifiable). For instance, it can be falsified by examining the spatial correlation of IR-related gene expression and $A \beta$ and Tau pathologies in brain specimens from subjects across the spectrum from normal cognition to AD. Moreover, it allows for novel predictions that can be tested in clinical trials. For instance, interventions that increase insulin sensitivity (see below) may be expected to decrease the rate of $A \beta$ production and tau hyperphosphorylation. For these predictions to be testable though, biomarkers that reflect $\mathrm{AD}$ pathogenic processes, brain metabolism and IR are required.

\section{TRADITIONAL AND NOVEL BIOCHEMICAL MEASURES OF INSULIN RESISTANCE}

The traditional gold standard for measuring systemic IR is the hyperinsulinemic euglycemic clamp, as this technique provides highly reproducible data with a distinct physiological meaning (DeFronzo et al., 1979). Unfortunately, the technique is procedurally complex and requires considerable expertise to obtain reliable results (Le et al., 2009). HOMA-IR, as well as its most recent version HOMA2-IR, provide an estimate of systemic IR and $\beta$ cell function by combining fasting insulin and glucose levels in a single metric (Matthews et al., 1985). IR as measured by HOMA-IR (see below) has been shown to correlate with increased CSF levels of AD biomarkers such as soluble amyloid precursor protein $\beta$ (sAPP $\beta$ ), p-tau181 and A $\beta 42$ (Starks et al., 2015; Hoscheidt et al., 2016). Unfortunately, HOMA-IR is subject to measurement errors especially if a single blood sample is used and is also susceptible to physiological fluctuations in fasting glucose and insulin levels, limiting its reliability. Moreover, HOMA-IR does not distinguish between brain-specific and systemic IR, making the search for biomarkers directly reflecting brain phenomena imperative for studying the role of IR in AD.

EVs are membranous particles and are secreted from nearly every cell type throughout the body, whereas the term exosomes refers to a subtype of EVs from $30 \mathrm{~nm}$ to $150 \mathrm{~nm}$ in size that have been implicated in a variety of functions. EVs extracted from murine brain tissue have been shown to contain APP, as well as $\mathrm{A} \beta$ species (Bellingham et al., 2012; Perez-Gonzalez et al., 2012) Moreover, secreted exosomes have been shown to contain hyperphosphorylated tau as well as $\mathrm{A} \beta$ (Rajendran et al., 2006). Interestingly, EVs also contain proteolytically active IDE which may degrade extracellular A $\beta$ (Bulloj et al., 2010).

Whereas these and subsequent findings implicated EVs in $\mathrm{AD}$ pathogenesis, we are primarily interested in EVs as a source of biomarkers for the disease. Our team has been a pioneer in isolating plasma EVs enriched for neuronal origin. To date, AD biomarkers derived from neuronal origin-enriched EVs include not only the main pathogenic proteins ( $\mathrm{p}$-tau and A $\beta 42$ ) but also intracellular signaling molecules, such as phosphorylated IRS-1, Cathepsin-D, REST, LRP6, and others (Fiandaca et al., 2015; Goetzl et al., 2015a,b; Kapogiannis et al., 2015). Of particular interest for the study of brain IR are our findings concerning IRS-1. In plasma EVs enriched for neuronal origin, we measured total, pSer312- and p-PanY- (pan-Tyr phosphorylated) IRS-1 in a clinical cohort of $\mathrm{AD}$ patients and $\mathrm{CN}$ older control subjects (as well as patients with Frontotemporal Dementia, as a neurodegenerative disease control, and $\mathrm{CN}$ patients with diabetes, as a metabolic disease control). We showed that these two phospho-species, as well as their ratio, were highly significantly different in $\mathrm{AD}$ patients vs. all control groups. Interestingly, subjects with diabetes had intermediate values between $\mathrm{AD}$ patients and $\mathrm{CN}$ controls, suggesting that the peripheral IR that characterizes diabetes is linked to some degree to brain IR and corroborating the extensive body of literature suggesting that IR and diabetes are risk factors for $\mathrm{AD}$, but by no means obligatory causative factors. Furthermore, IRS-1 phospho-species achieved remarkable classification accuracy for $\mathrm{AD}$ patients vs. controls, and in a separate smaller cohort were already abnormal up to 10 years before clinical onset of $\mathrm{AD}$ (Kapogiannis et al., 2015).

In a recent study Mullins et al. (2017), we showed that, in a cohort of AD patients without systemic IR, pSer312-IRS-1 was positively associated with MRI atrophy, whereas p-PanYIRS-1 was negatively associated with it, in a highly characteristic pattern of regions. The significance of this regional pattern lies in its spatial correlation with the normal IRS-1 brain expression. We speculate that neuronal-enriched plasma EVs containing IRS-1 may be preferentially derived from brain regions with high levels of IRS-1 expression. Therefore, the IRS-1 phosphorylation pattern seen in these EVs may reflect its phosphorylation status in specific brain regions that suffer brain atrophy in early $\mathrm{AD}$ in association with higher burden of brain IR. Interestingly, systemic IR (either in terms of fasting insulin or HOMAIR) showed no associations with regional AD atrophy, further suggesting that EV-based biomarkers are well- suited as a tool for investigating brain IR in AD. These findings not only further establish the links between IR and AD, but provide hope for a blood-based diagnostic assay to identify individuals who would likely develop AD preclinically. Importantly, since interventions that aim to reverse brain IR in $\mathrm{AD}$ are being subjected to clinical trials (e.g., intranasal insulin, exenatide), using these biomarkers we may be able to demonstrate target engagement and follow response to treatment.

\section{NEUROIMAGING STUDIES OF INSULIN RESISTANCE}

Fluorodeoxyglucose Positron emission tomography (FDG-PET) imaging has long been considered the definitive method for assessing brain metabolism. FDG is an analog of glucose that is imported in cells in a similar fashion to glucose that provides 
a reliable estimate of the cerebral metabolic rate for glucose (CMRGlc). As was initially shown in 1989 (Friedland et al., 1989) and replicated in numerous cohorts since (Herholz et al., 2002; Langbaum et al., 2009), CMRGlc is decreased in AD with a characteristic regional pattern over the medial/lateral parietotemporal and frontal cortices. Intriguingly, the same pattern of relative hypometabolism was shown in relation to HOMA-IR in CN post-menopausal women (Rasgon et al., 2014), older adults with prediabetes/T2D (Baker et al., 2011), and those at higher risk for $\mathrm{AD}$ given their parental history (Willette et al., 2015a). This suggests a continuum of vulnerability of glucose metabolism in these conditions that culminates in clinical AD. In a study of patients with $\mathrm{MCI}$ and $\mathrm{AD}$, we showed that HOMA-IR is negatively associated with glucose metabolism in brain areas vulnerable to AD pathology, but not in areas typically unaffected by $\mathrm{AD}$ (Willette et al., 2015c). In addition, we showed that HOMA-IR is paradoxically (and perhaps maladaptively) positively associated with hippocampal glucose metabolism in MCI patients prior to conversion to $\mathrm{AD}$ dementia (Willette et al., 2015c).

Conflicting findings exist on the relationship between $A \beta$ deposition and peripheral IR in PET studies using Pittsburgh compound $\mathrm{B}(\mathrm{PiB})$ or Florbetapir (F18-AV-45), with some studies showing no such relationship (Edison et al., 2007; Thambisetty et al., 2013) and others indicating a relationship for normoglycemic but not hyperglycemic CN older adults (Willette et al., 2015b). The recent development of tau-PET imaging has attracted a surge of interest due to recent findings that it presents a stronger relation to neurodegeneration and cognitive decline than A $\beta$ (Sarazin et al., 2016; Thal and Vandenberghe, 2016), but being a very recent development there are no published results to report on the relation of tau distribution to IR.

Structural and functional MRI have also been used to study IR-AD associations. In late middle-aged, cognitively healthy individuals, HOMA-IR has been negatively associated with hippocampal (Rasgon et al., 2011) and cortical gray matter (Willette et al., 2013) volumes in a pattern characteristic of AD. Diffusion MRI has revealed deficits in the microstructural integrity of gray and white matter in AD (Meng et al., 2012; Hong et al., 2013; Molinuevo et al., 2014; Weston et al., 2015) and type 2 diabetes (Hsu et al., 2012; Reijmer et al., 2013; Xiong et al., 2016) that are associated with impaired cognitive performance. Functional MRI (fMRI) has been used to demonstrate that insulin infusion enhances activity in the medial temporal lobe (Zhao and Townsend, 2009), that middle-aged CN subjects with peripheral IR (Kenna et al., 2013) or type 2 diabetes (Musen et al., 2012; Chen et al., 2014) show impaired functional connectivity of the hippocampus and the default mode network, Advanced two-dimensional (2D MRS) methods currently gaining favor are capable of detecting glucose concentrations within specific regions of the brain (Thomas et al., 2003) and may be used some day to study IR in relation to AD. An example of this method is provided below.

As a general comment to all neuroimaging studies to date; since no good biomarker of brain IR existed, the field had to rely on the assumption that some peripheral IR measure (such as HOMA-IR) can be used as a surrogate of brain IR. With the discovery of IRS-1 phospho-peptides in neural-origin plasma EVs (Kapogiannis et al., 2015) and the demonstration of their neuroimaging correlates (Mullins et al., 2017), we have introduced biomarkers for brain-specific IR. We hope that future neuroimaging studies will take advantage of these novel biomarkers and examine more brain-specific associations.

\section{FUTURE DIRECTIONS: GLUCOSE MEASUREMENT VIA 2D MAGNETIC RESONANCE SPECTROSCOPY}

Modern magnetic resonance spectroscopy (MRS) techniques have recently advanced to the point of reliable measurement of in vivo glucose levels in the brain. Earlier 1D MRS methods had difficulty quantifying the glucose metabolite signal due to the presence of multiple overlapping signals in the acquired spectra (Steinberg and Velan, 2013). The method of $2 \mathrm{D}$ junctional point-resolved spectroscopy (J-PRESS) solves this problem by sampling the signal at multiple echo times, which adds another dimension to the spectra to increase specificity and reduce overlapping peak tails (see Figure 3B for spectral fitting; Schulte and Boesiger, 2006). This increased specificity is of particular interest for neurotransmitters and metabolites linked to $\mathrm{AD}$ pathogenesis, particularly glucose (Kapogiannis et al., 2013). The J-PRESS technique thus presents researchers with the opportunity to safely estimate the actual in vivo level of combined intracellular and extracellular brain glucose. Therefore, this measure may complement information acquired with FDG-PET, which assesses the metabolic rate of glucose rather than its concentration. In comparison to PET, MRS has the advantage of not using radiation and potentially being more widely available, since it requires only MR scanning rather than nuclear medicine capabilities.

To demonstrate technical feasibility and provide proof of concept for this method, we collected JPRESS data from a set of 15 fasting healthy male volunteer participants $(40.5 \pm 7.8$ years old) who also underwent a blood draw for fasting glucose. Both the MRS and the blood draws took place after an 8-h fast. Plasma samples were processed via YSI 2300 STAT PLUS $^{\mathrm{TM}}$ Glucose analyzer (YSI Inc., Yellow Springs, OH, USA) to derive glucose concentration. A 2D J-PRESS acquisition with maximum-echo sampling was used to acquire metabolite concentrations from a bilateral anisotropic precuneus Voxel $\left(25 \times 18 \times 20 \mathrm{~mm}^{3}\right.$, see Figure $\left.\mathbf{3 A}\right)$, also used in our previous study (Kapogiannis et al., 2013). ProFit software (Schulte and Boesiger, 2006) was used to acquire the linear combinations of simulated basis metabolite spectra to generate relative concentrations to creatine. All data were acquired as part of the visit for a physiology study on glucose metabolism (ClinicalTrials.gov Identifier NCT01517100) and approved by the Institutional Review Board of the National Institute of Diabetes and Digestive and Kidney Diseases, Bethesda, MD, USA. All participants provided written informed consent. 
We found that glucose concentration was reliably measured in all 15 subjects, with a mean Cramer-Rao lower bound (crlb\%, a measure of signal reliability) of $13.7 \%$, ranging from $7.6 \%$ to $21.8 \%$. In addition, we found a moderate negative correlation between MRS Glc brain concentrations and fasting glucose levels $(r=-0.546, p=0.035$; Figure 3C). The exact significance of this finding and its pertinence to disease states is the subject of ongoing research. As the MRS acquisition spans about $24 \mathrm{~min}$, MRS Glc likely reflects steady state glucose levels. One possible explanation is that higher brain MRS Glc results from lower brain glucose metabolism. It is known that, during prolonged fasting (after $12 \mathrm{~h}$ ), the body (and the brain) switches from glucose to ketone metabolism (Foster, 1967). It has been shown that ketones are the preferred energy source by the brain, since the higher their plasma concentration, the higher their uptake by the brain, and the higher their percent contribution to total brain energy metabolism (Cunnane et al., 2016a,b). Subjects with lower fasting plasma glucose during prolonged fasting may have switched more fully into brain ketone metabolism, with a corresponding decrease in brain glucose metabolism and increase in MRS Glc concentration. This hypothesis will be tested in an ongoing clinical study on the brain effects of intermittently prolonged calorie restriction (5-2 calorie restriction), which examines the effects of the diet on MRS glucose vis a vis levels of metabolites in CSF and plasma (NCT02460783). More broadly, this technique opens yet another window into brain metabolism for examining the effects of disease states, such as $\mathrm{AD}$.

\section{CLINICAL TRIALS TARGETING BRAIN IR IN AD AND BIOMARKERS}

There are several approaches for targeting brain IR as a therapeutic strategy for AD. Perhaps, the most straightforward one is to try to overcome brain IR by increasing brain availability of insulin. Since systemic insulin administration in non-diabetic subjects produces hypoglycemia, the approach that has been promoted to achieve this goal is intranasal insulin administration, which involves bulk flow through the olfactory bulb into the brain (Born et al., 2002). In a Phase II clinical trial, patients receiving intranasal insulin for 4 months showed better cognition (especially memory) compared to those receiving placebo (Craft et al., 2012). A recent study using the long-acting insulin analog detemir via intranasal administration also yielded promising results (Claxton et al., 2015). A different strategy is brain insulin sensitization; two insulin-sensitizing drugs, rosiglitazone and pioglitazone, are currently being investigated as therapeutic agents for $\mathrm{AD}$. Rosiglitazone potentiates the protective effects of insulin on cultured neurons and inhibits the production of $A \beta 42$ in mice, but human trials have yielded disappointing results (Landreth et al., 2008; De Felice et al., 2009; Miller et al., 2011). In mice, pioglitazone improves learning, reduces tau and $A \beta$ deposits in the hippocampus, and improves neuronal plasticity (Searcy et al., 2012). In humans, consistent pioglitazone administration has been associated with decreased incidence of dementia, but clinical trials are lacking (Heneka et al., 2015).
Glucagon like peptide 1 (GLP1) agonists have been shown to offer neuroprotection (Perry et al., 2002, 2007), reverse brain IR (Bomfim et al., 2012; Talbot and Wang, 2014), decrease $\mathrm{A} \beta$ and tau levels and deposits (Li et al., 2010; McClean et al., 2011), and decrease tau hyper-phosphorylation (Xu et al., 2015) in multiple cellular and animal models of AD. The GLP-1 agonist exenatide, has been shown to alleviate brain IR in AD by modifying the pattern of IRS-1 phosphorylation (Bomfim et al., 2012) and be neuroprotective against a variety of neurodegenerative diseases and stroke (Li et al., 2009; Martin et al., 2009; Tweedie et al., 2012). Importantly, exenatide has already demonstrated clinical effectiveness for Parkinson disease in terms of motor and cognitive performance measures (AvilesOlmos et al., 2013). Our team recently completed a pilot clinical trial of exenatide in MCI/early AD (NCT01255163). Recently, it was reported that $\mathrm{AD}$ patients treated with another GLP-1 agonist, liraglutide, for 6 months showed a non-significant trend for increased CMRglc compared to placebo-treated patients. Importantly, the rate of progressive $\mathrm{A} \beta$ deposition in $\mathrm{PiB}$ PET was not affected by the treatment. The authors note that the findings are inconclusive in regard to the therapeutic potential of liraglutide, and by extension of GLP1 agonists, in $\mathrm{AD}$ (Gejl et al., 2016). In our view, this inconclusiveness stems from the limited relevance of the outcome measures to the mechanism of action of the intervention. Relying on cognitive/clinical outcomes or even biomarker outcomes far down-stream in the pathogenic cascade and relevant only to one particular aspect of disease pathogenesis (such as PiB PET) irrespective of the particular mechanism involved has plagued clinical trials in $\mathrm{AD}$ and prevented the field from extracting generalizable conclusions from the failures in individual clinical trials.

We are currently engaged in the analysis of IRS-1 phosphotypes and downstream signaling molecules in neuronal EVs from plasma samples from the pilot trial of exenatide in $\mathrm{AD}$ conducted at the National Institute on Aging (NIA) and several other clinical trials targeting IR. We are hopeful that a response of EV-based biomarkers and/or MRS Glc to experimental interventions would demonstrate mechanism-specific target engagement. In addition, if these interventions decrease $A \beta$ production and tau phosphorylation, they would provide significant mechanistic support to the hypothetical paradigm advocated in this article.

\section{CONCLUSIONS}

This article attempted to disentangle the complex mechanisms underlying brain IR, highlight proven or plausible links to $A \beta$ and tau pathologies in $\mathrm{AD}$, as well as provide information about promising recent EV-based biomarkers, in vivo glucose MRS measures, and gene array neuroinformatics techniques. The convergence of such diverse sources of evidence makes it all but certain that brain IR plays a major role in $\mathrm{AD}$ pathogenesis linking the two main types of pathology (Figure 4). Ultimately, the merit of this hypothesis rests on demonstrating effectiveness in ongoing and future clinical trials. 


\section{AUTHOR CONTRIBUTIONS}

RJM, TCD, CWC and DK wrote and edited the manuscript; RJM, TCD and DK were responsible for experimental design and conception; and RJM performed the analyses.

\section{REFERENCES}

Aguirre, V., Werner, E. D., Giraud, J., Lee, Y. H., Shoelson, S. E., and White, M. F. (2002). Phosphorylation of Ser307 in insulin receptor substrate-1 blocks interactions with the insulin receptor and inhibits insulin action. J. Biol. Chem. 277, 1531-1537. doi: 10.1074/jbc.m101521200

Apelt, J., Mehlhorn, G., and Schliebs, R. (1999). Insulin-sensitive GLUT4 glucose transporters are colocalized with GLUT3-expressing cells and demonstrate a chemically distinct neuron-specific localization in rat brain. J. Neurosci. Res. 57, 693-705. doi: 10.1002/(sici)1097-4547(19990901)57:5<693::aid-jnr11>3.0. $\mathrm{co} ; 2-\mathrm{x}$

Arnold, S. E., Hyman, B. T., Flory, J., Damasio, A. R., and Van Hoesen, G. W. (1991). The topographical and neuroanatomical distribution of neurofibrillary tangles and neuritic plaques in the cerebral cortex of patients with Alzheimer's disease. Cereb. Cortex 1, 103-116. doi: 10.1093/cercor/1.1.103

Arvanitakis, Z., Wilson, R. S., Bienias, J. L., Evans, D. A., and Bennett, D. A. (2004). Diabetes mellitus and risk of Alzheimer disease and decline in cognitive function. Arch. Neurol. 61, 661-666. doi: 10.1001/archneur.61.5.661

Asakawa, A., Inui, A., Inui, T., Katsuura, G., Fujino, M. A., and Kasuga, M. (2003). Leptin treatment ameliorates anxiety in ob/ob obese mice. J. Diabetes Complicat. 17, 105-107. doi: 10.1016/s1056-8727(02)00185-x

Attems, J., and Jellinger, K. A. (2014). The overlap between vascular disease and Alzheimer's disease-lessons from pathology. BMC Med. 12:206. doi: 10.1186/s12916-014-0206-2

Authier, F., Posner, B. I., and Bergeron, J. J. (1996). Insulin-degrading enzyme. Clin. Invest. Med. 19, 149-160.

Aviles-Olmos, I., Dickson, J., Kefalopoulou, Z., Djamshidian, A., Ell, P., Soderlund, T., et al. (2013). Exenatide and the treatment of patients with Parkinson's disease. J. Clin. Invest. 123, 2730-2736. doi: 10.1172/JCI68295

Baker, L. D., Cross, D. J., Minoshima, S., Belongia, D., Watson, G. S., and Craft, S. (2011). Insulin resistance and Alzheimer-like reductions in regional cerebral glucose metabolism for cognitively normal adults with prediabetes or early type 2 diabetes. Arch. Neurol. 68, 51-57. doi: 10.1001/archneurol.2010.225

Banks, W. A. (2004). The source of cerebral insulin. Eur. J. Pharmacol. 490, 5-12. doi: 10.1016/j.ejphar.2004.02.040

Banks, W. A., Owen, J. B., and Erickson, M. A. (2012). Insulin in the brain: there and back again. Pharmacol. Ther. 136, 82-93. doi: 10.1016/j.pharmthera.2012. 07.006

Battistin, L., and Cagnin, A. (2010). Vascular cognitive disorder. A biological and clinical overview. Neurochem. Res. 35, 1933-1938. doi: 10.1007/s11064-0100346-5

Bellingham, S. A., Guo, B. B., Coleman, B. M., and Hill, A. F. (2012). Exosomes: vehicles for the transfer of toxic proteins associated with neurodegenerative diseases? Front. Physiol. 3:124. doi: 10.3389/fphys.2012.00124

Bero, A. W., Yan, P., Roh, J. H., Cirrito, J. R., Stewart, F. R., Raichle, M. E., et al. (2011). Neuronal activity regulates the regional vulnerability to amyloid- $\beta$ deposition. Nat. Neurosci. 14, 750-756. doi: 10.1038/nn.2801

Blázquez, E., Velázquez, E., Hurtado-Carneiro, V., and Ruiz-Albusac, J. M. (2014). Insulin in the brain: its pathophysiological implications for States related with central insulin resistance, type 2 diabetes and Alzheimer's disease. Front. Endocrinol. Lausanne. 5:161. doi: 10.3389/fendo.2014.00161

Blennow, K. (2004). Cerebrospinal fluid protein biomarkers for Alzheimer's disease. NeuroRx 1, 213-225. doi: 10.1602/neurorx.1.2.213

Bomfim, T. R., Forny-Germano, L., Sathler, L. B., Brito-Moreira, J., Houzel, J. C., Decker, H., et al. (2012). An anti-diabetes agent protects the mouse brain from defective insulin signaling caused by Alzheimer's disease- associated $\mathrm{A} \beta$ oligomers. J. Clin. Invest. 122, 1339-1353. doi: 10.1172/JCI57256

Born, J., Lange, T., Kern, W., McGregor, G. P., Bickel, U., and Fehm, H. L. (2002). Sniffing neuropeptides: a transnasal approach to the human brain. Nat. Neurosci. 5, 514-516. doi: 10.1038/nn0602-849

\section{ACKNOWLEDGMENTS}

This research was supported entirely by the Intramural Research Program of the National Institute on Aging, NIH.

Boura-Halfon, S., and Zick, Y. (2009). Phosphorylation of IRS proteins, insulin action and insulin resistance. Am. J. Physiol. Endocrinol. Metab. 296, E581-E591. doi: 10.1152/ajpendo.90437.2008

Brandt, R., and Leschik, J. (2004). Functional interactions of tau and their relevance for Alzheimer's disease. Curr. Alzheimer Res. 1, 255-269. doi: $10.2174 / 1567205043332054$

Breteler, M. M. (2000). Vascular involvement in cognitive decline and dementia. Epidemiologic evidence from the Rotterdam Study and the Rotterdam Scan Study. Ann. N Y Acad. Sci. 903, 457-465. doi: 10.1111/j.1749-6632.2000. tb06399.x

Bulloj, A., Leal, M. C., Xu, H., Castaño, E. M., and Morelli, L. (2010). Insulindegrading enzyme sorting in exosomes: a secretory pathway for a key brain amyloid- $\beta$ degrading protease. J. Alzheimers Dis. 19, 79-95. doi: 10.3233/JAD2010-1206

Cai, Z., Wang, C., He, W., Tu, H., Tang, Z., Xiao, M., et al. (2015). Cerebral small vessel disease and Alzheimer's disease. Clin. Interv. Aging 10, 1695-1704. doi: 10.2147/CIA.S90871

Caro, J. F., Kolaczynski, J. W., Nyce, M. R., Ohannesian, J. P., Opentanova, I., Goldman, W. H., et al. (1996). Decreased cerebrospinal-fluid/serum leptin ratio in obesity: a possible mechanism for leptin resistance. Lancet 348, 159-161. doi: 10.1016/s0140-6736(96)03173-x

Celermajer, D. S. (1997). Endothelial dysfunction: does it matter? Is it reversible? J. Am. Coll. Cardiol. 30, 325-333. doi: 10.1016/S0735-1097(97)00189-7

Cersosimo, E., and DeFronzo, R. A. (2006). Insulin resistance and endothelial dysfunction: the road map to cardiovascular diseases. Diabetes Metab. Res. Rev. 22, 423-436. doi: 10.1002/dmrr.634

Chen, Y. C., Jiao, Y., Cui, Y., Shang, S. A., Ding, J., Feng, Y., et al. (2014). Aberrant brain functional connectivity related to insulin resistance in type 2 diabetes: a resting-state fMRI study. Diabetes Care 37, 1689-1696. doi: 10.2337/ dc13-2127

Chen, G. J., Xu, J., Lahousse, S. A., Caggiano, N. L., and de la Monte, S. M. (2003). Transient hypoxia causes Alzheimer-type molecular and biochemical abnormalities in cortical neurons: potential strategies for neuroprotection. J. Alzheimers Dis. 5, 209-228. doi: 10.3233/jad-2003-5305

Clarke, J. R., Lyra, E. S. N. M., Figueiredo, C. P., Frozza, R. L., Ledo, J. H., Beckman, D., et al. (2015). Alzheimer-associated A $\beta$ oligomers impact the central nervous system to induce peripheral metabolic deregulation. $E M B O$ Mol. Med. 7, 190-210. doi: 10.15252/emmm.201404183

Claxton, A., Baker, L. D., Hanson, A., Trittschuh, E. H., Cholerton, B., Morgan, A., et al. (2015). Long-acting intranasal insulin detemir improves cognition for adults with mild cognitive impairment or early-stage Alzheimer's disease dementia. J. Alzheimers Dis. 44, 897-906. doi: 10.3233/JAD-141791

Clodfelder-Miller, B. J., Zmijewska, A. A., Johnson, G. V., and Jope, R. S. (2006). Tau is hyperphosphorylated at multiple sites in mouse brain in vivo after streptozotocin-induced insulin deficiency. Diabetes 55, 3320-3325. doi: $10.2337 / \mathrm{db} 06-0485$

Copps, K. D., Hancer, N. J., Opare-Ado, L., Qiu, W., Walsh, C., and White, M. F. (2010). Irs1 serine 307 promotes insulin sensitivity in mice. Cell Metab. 11, 84-92. doi: 10.1016/j.cmet.2009.11.003

Copps, K. D., and White, M. F. (2012). Regulation of insulin sensitivity by serine/threonine phosphorylation of insulin receptor substrate proteins IRS1 and IRS2. Diabetologia 55, 2565-2582. doi: 10.1007/s00125-012-2644-8

Cornford, E. M., and Hyman, S. (2005). Localization of brain endothelial luminal and abluminal transporters with immunogold electron microscopy. NeuroRx 2 , 27-43. doi: 10.1602/neurorx.2.1.27

Corriveau, R. A., Bosetti, F., Emr, M., Gladman, J. T., Koenig, J. I., Moy, C. S., et al. (2016). The science of vascular contributions to cognitive impairment and dementia (VCID): a framework for advancing research priorities in the cerebrovascular biology of cognitive decline. Cell. Mol. Neurobiol. 36, 281-288. doi: 10.1007/s10571-016-0334-7 
Craft, S., Baker, L. D., Montine, T. J., Minoshima, S., Watson, G. S., Claxton, A., et al. (2012). Intranasal insulin therapy for Alzheimer disease and amnestic mild cognitive impairment: a pilot clinical trial. Arch. Neurol. 69, 29-38. doi: 10.1001/archneurol.2011.233

Cunnane, S. C., Courchesne-Loyer, A., St-Pierre, V., Vandenberghe, C., Pierotti, T., Fortier, M., et al. (2016a). Can ketones compensate for deteriorating brain glucose uptake during aging? Implications for the risk and treatment of Alzheimer's disease. Ann. N Y Acad. Sci. 1367, 12-20. doi: 10.1111/nyas. 12999

Cunnane, S. C., Courchesne-Loyer, A., Vandenberghe, C., St-Pierre, V., Fortier, M., Hennebelle, M., et al. (2016b). Can ketones help rescue brain fuel supply in later life? Implications for cognitive health during aging and the treatment of Alzheimer's disease. Front. Mol. Neurosci. 9:53. doi: 10.3389/fnmol.2016.00053

Czech, M. P., Klarlund, J. K., Yagaloff, K. A., Bradford, A. P., and Lewis, R. E. (1988). Insulin receptor signaling. Activation of multiple serine kinases. J. Biol. Chem. 263, 11017-11020.

Daneman, R. (2012). The blood-brain barrier in health and disease. Ann. Neurol. 72, 648-672. doi: 10.1002/ana.23648

Davì, G., Guagnano, M. T., Ciabattoni, G., Basili, S., Falco, A., Marinopiccoli, M., et al. (2002). Platelet activation in obese women: role of inflammation and oxidant stress. JAMA 288, 2008-2014. doi: 10.1001/jama.288.16.2008

Dearborn, J. L., Schneider, A. L., Sharrett, A. R., Mosley, T. H., Bezerra, D. C., Knopman, D. S., et al. (2015). Obesity, insulin resistance, and incident small vessel disease on magnetic resonance imaging: atherosclerosis risk in communities study. Stroke 46, 3131-3136. doi: 10.1161/STROKEAHA.115. 010060

De Felice, F. G., Lourenco, M. V., and Ferreira, S. T. (2014). How does brain insulin resistance develop in Alzheimer's disease? Alzheimers Dement. 10, S26-S32. doi: 10.1016/j.jalz.2013.12.004

De Felice, F. G., Vieira, M. N., Bomfim, T. R., Decker, H., Velasco, P. T., Lambert, M. P., et al. (2009). Protection of synapses against Alzheimer's-linked toxins: insulin signaling prevents the pathogenic binding of $\mathrm{A} \beta$ oligomers. Proc. Natl. Acad. Sci. U S A 106, 1971-1976. doi: 10.1073/pnas.0809158106

DeFronzo, R. A., Tobin, J. D., and Andres, R. (1979). Glucose clamp technique: a method for quantifying insulin secretion and resistance. Am. J. Physiol. 237, E214-E223.

de la Monte, S. M. (2012). Contributions of brain insulin resistance and deficiency in amyloid-related neurodegeneration in Alzheimer's disease. Drugs 72, 49-66. doi: 10.2165/11597760-000000000-00000

Deng, J., Habib, A., Obregon, D. F., Barger, S. W., Giunta, B., Wang, Y. J., et al. (2015). Soluble amyloid precursor protein alpha inhibits tau phosphorylation through modulation of GSK3 $\beta$ signaling pathway. J. Neurochem. 135, 630-637. doi: $10.1111 /$ jnc. 13351

Devaskar, S. U., Giddings, S. J., Rajakumar, P. A., Carnaghi, L. R., Menon, R. K., and Zahm, D. S. (1994). Insulin gene expression and insulin synthesis in mammalian neuronal cells. J. Biol. Chem. 269, 8445-8454.

Dinel, A. L., André, C., Aubert, A., Ferreira, G., Layé, S., and Castanon, N. (2011). Cognitive and emotional alterations are related to hippocampal inflammation in a mouse model of metabolic syndrome. PLoS One 6:e24325. doi: 10.1371/journal.pone.0024325

Draznin, B. (2006). Molecular mechanisms of insulin resistance: serine phosphorylation of insulin receptor substrate- 1 and increased expression of p85a: the two sides of a coin. Diabetes 55, 2392-2397. doi: 10.2337/db06-0391

Duarte, A. I., Moreira, P. I., and Oliveira, C. R. (2012). Insulin in central nervous system: more than just a peripheral hormone. J. Aging Res. 2012:384017. doi: $10.1155 / 2012 / 384017$

Duelli, R., and Kuschinsky, W. (2001). Brain glucose transporters: relationship to local energy demand. News Physiol. Sci. 16, 71-76.

Edison, P., Archer, H. A., Hinz, R., Hammers, A., Pavese, N., Tai, Y. F., et al. (2007). Amyloid, hypometabolism and cognition in Alzheimer disease: an [11C]PIB and [18F]FDG PET study. Neurology 68, 501-508. doi: 10.1212/01. wnl.0000244749.20056.d4

Edland, S. D. (2004). Insulin-degrading enzyme, apolipoprotein E, and Alzheimer's disease. J. Mol. Neurosci. 23, 213-217. doi: 10.1385/JMN:23:3:213

Eldar-Finkelman, H., and Krebs, E. G. (1997). Phosphorylation of insulin receptor substrate 1 by glycogen synthase kinase 3 impairs insulin action. Proc. Natl. Acad. Sci. U S A 94, 9660-9664. doi: 10.1073/pnas.94.18.9660
Fiandaca, M. S., Kapogiannis, D., Mapstone, M., Boxer, A., Eitan, E., Schwartz, J. B., et al. (2015). Identification of preclinical Alzheimer's disease by a profile of pathogenic proteins in neurally derived blood exosomes: a case-control study. Alzheimers Dement. 11, 600-607.e1. doi: 10.1016/j.jalz. 2014.06.008

Foster, D. W. (1967). Studies in the ketosis of fasting. J. Clin. Invest. 46, 1283-1296. doi: $10.1172 /$ JCI105621

Francis, S. H., Busch, J. L., Corbin, J. D., and Sibley, D. (2010). cGMP-dependent protein kinases and cGMP phosphodiesterases in nitric oxide and cGMP action. Pharmacol. Rev. 62, 525-563. doi: 10.1124/pr.110.002907

Friedland, R. P., Jagust, W. J., Huesman, R. H., Koss, E., Knittel, B., Mathis, C. A., et al. (1989). Regional cerebral glucose transport and utilization in Alzheimer's disease. Neurology 39, 1427-1434. doi: 10.1212/WNL.39.11.1427

Fröjdö, S., Vidal, H., and Pirola, L. (2009). Alterations of insulin signaling in type 2 diabetes: a review of the current evidence from humans. Biochim. Biophys. Acta 1792, 83-92. doi: 10.1016/j.bbadis.2008.10.019

Frölich, L., Blum-Degen, D., Bernstein, H. G., Engelsberger, S., Humrich, J., Laufer, S., et al. (1998). Brain insulin and insulin receptors in aging and sporadic Alzheimer's disease. J. Neural Transm. (Vienna) 105, 423-438. doi: $10.1007 /$ s007020050068

Gejl, M., Gjedde, A., Egefjord, L., Møller, A., Hansen, S. B., Vang, K., et al. (2016). In Alzheimer's disease, 6-month treatment with GLP-1 analog prevents decline of brain glucose metabolism: randomized, placebo-controlled, double-blind clinical trial. Front. Aging Neurosci. 8:108. doi: 10.3389/fnagi.2016.00108

Genders, A. J., Frison, V., Abramson, S. R., and Barrett, E. J. (2013). Endothelial cells actively concentrate insulin during its transendothelial transport. Microcirculation 20, 434-439. doi: 10.1111/micc.12044

Ginsberg, H. N. (2000). Insulin resistance and cardiovascular disease. J. Clin. Invest. 106, 453-458. doi: 10.1172/JCI10762

Goetzl, E. J., Boxer, A., Schwartz, J. B., Abner, E. L., Petersen, R. C., Miller, B. L., et al. (2015a). Low neural exosomal levels of cellular survival factors in Alzheimer's disease. Ann. Clin. Transl. Neurol. 2, 769-773. doi: 10.1002/ acn 3.211

Goetzl, E. J., Boxer, A., Schwartz, J. B., Abner, E. L., Petersen, R. C., Miller, B. L., et al. (2015b). Altered lysosomal proteins in neural-derived plasma exosomes in preclinical Alzheimer disease. Neurology 85, 40-47. doi: 10.1212/WNL. 0000000000001702

Gong, C. X., Shaikh, S., Wang, J. Z., Zaidi, T., Grundke-Iqbal, I., and Iqbal, K. (1995). Phosphatase activity toward abnormally phosphorylated tau: decrease in Alzheimer disease brain. J. Neurochem. 65, 732-738. doi: 10.1046/j.14714159.1995.65020732.x

Gorelick, P. B., Scuteri, A., Black, S. E., Decarli, C., Greenberg, S. M., Iadecola, C., et al. (2011). Vascular contributions to cognitive impairment and dementia: a statement for healthcare professionals from the american heart association/american stroke association. Stroke 42, 2672-2713. doi: 10.1161/STR.0b013e3182299496

Greenwald, J., and Riek, R. (2010). Biology of amyloid: structure, function and regulation. Structure 18, 1244-1260. doi: 10.1016/j.str.2010.08.009

Grillo, C. A., Piroli, G. G., Kaigler, K. F., Wilson, S. P., Wilson, M. A., and Reagan, L. P. (2011). Downregulation of hypothalamic insulin receptor expression elicits depressive-like behaviors in rats. Behav. Brain Res. 222, 230-235. doi: 10.1016/j.bbr.2011.03.052

Grillo, C. A., Piroli, G. G., Lawrence, R. C., Wrighten, S. A., Green, A. J., Wilson, S. P., et al. (2015). Hippocampal insulin resistance impairs spatial learning and synaptic plasticity. Diabetes 64, 3927-3936. doi: 10.2337/db 15-0596

Grünblatt, E., Salkovic-Petrisic, M., Osmanovic, J., Riederer, P., and Hoyer, S. (2007). Brain insulin system dysfunction in streptozotocin intracerebroventricularly treated rats generates hyperphosphorylated tau protein. J. Neurochem. 101, 757-770. doi: 10.1111/j.1471-4159.2006.04368.x

Hardy, J., and Selkoe, D. J. (2002). The amyloid hypothesis of Alzheimer's disease: progress and problems on the road to therapeutics. Science 297, 353-356. doi: 10.1126/science.1072994

Harris, R. A., Tindale, L., Lone, A., Singh, O., Macauley, S. L., Stanley, M., et al. (2016). Aerobic glycolysis in the frontal cortex correlates with memory performance in wild-type mice but not the APP/PS1 mouse model of cerebral amyloidosis. J. Neurosci. 36, 1871-1878. doi: 10.1523/JNEUROSCI.313115.2016 
Havrankova, J., Roth, J., and Brownstein, M. (1978). Insulin receptors are widely distributed in the central nervous system of the rat. Nature 272, 827-829. doi: $10.1038 / 272827 \mathrm{a} 0$

Havrankova, J., Roth, J., and Brownstein, M. J. (1979). Concentrations of insulin and insulin receptors in the brain are independent of peripheral insulin levels. Studies of obese and streptozotocin-treated rodents. J. Clin. Invest. 64, 636-642. doi: $10.1172 /$ jci109504

Hawrylycz, M. J., Lein, E. S., Guillozet-Bongaarts, A. L., Shen, E. H., Ng, L., Miller, J. A., et al. (2012). An anatomically comprehensive atlas of the adult human brain transcriptome. Nature 489, 391-399. doi: 10.1038/nature11405

Hawrylycz, M., Ng, L., Page, D., Morris, J., Lau, C., Faber, S., et al. (2011). Multiscale correlation structure of gene expression in the brain. Neural Netw. 24, 933-942. doi: 10.1016/j.neunet.2011.06.012

Heidenreich, K. A., and Gilmore, P. R. (1985). Structural and functional characteristics of insulin receptors in rat neuroblastoma cells. J. Neurochem. 45, 1642-1648. doi: 10.1111/j.1471-4159.1985.tb07237.x

Heneka, M. T., Fink, A., and Doblhammer, G. (2015). Effect of pioglitazone medication on the incidence of dementia. Ann. Neurol. 78, 284-294. doi: 10.1002/ana.24439

Heni, M., Kullmann, S., Preissl, H., Fritsche, A., and Haring, H. U. (2015). Impaired insulin action in the human brain: causes and metabolic consequences. Nat. Rev. Endocrinol. 11, 701-711. doi: 10.1038/nrendo. 2015.173

Herholz, K., Salmon, E., Perani, D., Baron, J. C., Holthoff, V., Frolich, L., et al. (2002). Discrimination between Alzheimer dementia and controls by automated analysis of multicenter FDG PET. Neuroimage 17, 302-316. doi: 10.1006/nimg.2002.1208

Hiltunen, M., Khandelwal, V. K., Yaluri, N., Tiilikainen, T., Tusa, M., Koivisto, H., et al. (2012). Contribution of genetic and dietary insulin resistance to Alzheimer phenotype in APP/PS1 transgenic mice. J. Cell. Mol. Med. 16, 1206-1222. doi: 10.1111/j.1582-4934.2011.01384.x

Ho, L., Qin, W., Pompl, P. N., Xiang, Z., Wang, J., Zhao, Z., et al. (2004). Diet-induced insulin resistance promotes amyloidosis in a transgenic mouse model of Alzheimer's disease. FASEB J. 18, 902-904. doi: 10.1096/fj.030978fje

Hong, M., and Lee, V. M. (1997). Insulin and insulin-like growth factor-1 regulate tau phosphorylation in cultured human neurons. J. Biol. Chem. 272, 19547-19553. doi: 10.1074/jbc.272.31.19547

Hong, Y. J., Yoon, B., Lim, S. C., Shim, Y. S., Kim, J. Y., Ahn, K. J., et al. (2013). Microstructural changes in the hippocampus and posterior cingulate in mild cognitive impairment and Alzheimer's disease: a diffusion tensor imaging study. Neurol. Sci. 34, 1215-1221. doi: 10.1007/s10072-012-1225-4

Hoscheidt, S. M., Starks, E. J., Oh, J. M., Zetterberg, H., Blennow, K., Krause, R. A., et al. (2016). Insulin resistance is associated with increased levels of cerebrospinal fluid biomarkers of Alzheimer's disease and reduced memory function in at-risk healthy middle-aged adults. J. Alzheimers Dis. 52, 1373-1383. doi: 10.3233/JAD-160110

Hsu, J. L., Chen, Y. L., Leu, J. G., Jaw, F. S., Lee, C. H., Tsai, Y. F., et al. (2012). Microstructural white matter abnormalities in type 2 diabetes mellitus: a diffusion tensor imaging study. Neuroimage 59, 1098-1105. doi: 10.1016/j. neuroimage.2011.09.041

Hsueh, W. A., Lyon, C. J., and Quiñones, M. J. (2004). Insulin resistance and the endothelium. Am. J. Med. 117, 109-117. doi: 10.1016/j.amjmed.2004.02.042

Hulse, R. E., Ralat, L. A., and Wei-Jen, T. (2009). Structure, function, and regulation of insulin-degrading enzyme. Vitam. Horm. 80, 635-648. doi: 10.1016/s0083-6729(08)00622-5

Jellinger, K. A. (2007). The enigma of mixed dementia. Alzheimers Dement. 3, 40-53. doi: 10.1016/j.jalz.2006.09.002

Julien, C., Tremblay, C., Phivilay, A., Berthiaume, L., Emond, V., Julien, P., et al. (2010). High-fat diet aggravates amyloid- $\beta$ and tau pathologies in the $3 \times \mathrm{Tg}-\mathrm{AD}$ mouse model. Neurobiol. Aging 31, 1516-1531. doi: 10.1016/j.neurobiolaging. 2008.08.022

Kapogiannis, D., Boxer, A., Schwartz, J. B., Abner, E. L., Biragyn, A., Masharani, U., et al. (2015). Dysfunctionally phosphorylated type 1 insulin receptor substrate in neural-derived blood exosomes of preclinical Alzheimer's disease. FASEB J. 29, 589-596. doi: 10.1096/fj.14-262048

Kapogiannis, D., Reiter, D. A., Willette, A. A., and Mattson, M. P. (2013). Posteromedial cortex glutamate and GABA predict intrinsic functional connectivity of the default mode network. Neuroimage 64, 112-119. doi: 10.1016/j.neuroimage.2012.09.029

Karapanayiotides, T., Piechowski-Jozwiak, B., van Melle, G., Bogousslavsky, J., and Devuyst, G. (2004). Stroke patterns, etiology, and prognosis in patients with diabetes mellitus. Neurology 62, 1558-1562. doi: 10.1212/01.wnl.0000123252. 55688.05

Keller, L., Xu, W., Wang, H. X., Winblad, B., Fratiglioni, L., and Graff, C. (2011). The obesity related gene, FTO, interacts with APOE and is associated with Alzheimer's disease risk: a prospective cohort study. J. Alzheimers Dis. 23, 461-469. doi: 10.3233/JAD-2010-101068

Kenna, H., Hoeft, F., Kelley, R., Wroolie, T., DeMuth, B., Reiss, A., et al. (2013). Fasting plasma insulin and the default mode network in women at risk for Alzheimer's disease. Neurobiol. Aging 34, 641-649. doi: 10.1016/j. neurobiolaging.2012.06.006

Kernan, W. N., Inzucchi, S. E., Viscoli, C. M., Brass, L. M., Bravata, D. M., Shulman, G. I., et al. (2003). Impaired insulin sensitivity among nondiabetic patients with a recent TIA or ischemic stroke. Neurology 60, 1447-1451. doi: 10.1212/01.wnl.0000063318.66140.a3

Kerouz, N. J., Hörsch, D., Pons, S., and Kahn, C. R. (1997). Differential regulation of insulin receptor substrates-1 and -2 (IRS-1 and IRS-2) and phosphatidylinositol 3-kinase isoforms in liver and muscle of the obese diabetic (ob/ob) mouse. J. Clin. Invest. 100, 3164-3172. doi: 10.1172/JCI 119872

Kim, B., Backus, C., Oh, S., and Feldman, E. L. (2013). Hyperglycemia-induced tau cleavage in vitro and in vivo: a possible link between diabetes and Alzheimer's disease. J. Alzheimers Dis. 34, 727-739. doi: 10.3233/JAD-121669

Kim, B., Backus, C., Oh, S., Hayes, J. M., and Feldman, E. L. (2009). Increased tau phosphorylation and cleavage in mouse models of type 1 and type 2 diabetes. Endocrinology 150, 5294-5301. doi: 10.1210/en.2009-0695

Kim, F., Tysseling, K. A., Rice, J., Pham, M., Haji, L., Gallis, B. M., et al. (2005). Free fatty acid impairment of nitric oxide production in endothelial cells is mediated by IKK $\beta$. Arterioscler. Thromb. Vasc. Biol. 25, 989-994. doi: 10.1161/01.ATV. 0000160549.60980.a8

Kins, S., Crameri, A., Evans, D. R., Hemmings, B. A., Nitsch, R. M., and Gotz, J. (2001). Reduced protein phosphatase 2A activity induces hyperphosphorylation and altered compartmentalization of tau in transgenic mice. J. Biol. Chem. 276, 38193-38200. doi: 10.1074/jbc.M102621200

Kling, M. A., Trojanowski, J. Q., Wolk, D. A., Lee, V. M., and Arnold, S. E. (2013). Vascular disease and dementias: paradigm shifts to drive research in new directions. Alzheimers Dement. 9, 76-92. doi: 10.1016/j.jalz.2012.02.007

Kook, S. Y., Hong, H. S., Moon, M., Ha, C. M., Chang, S., and Mook-Jung, I. (2012). $\mathrm{A} \beta_{1-42}$-RAGE interaction disrupts tight junctions of the blood-brain barrier via $\mathrm{Ca}^{2+}$-calcineurin signaling. J. Neurosci. 32, 8845-8854. doi: 10.1523/jneurosci. 6102-11.2012

Kos, K., Harte, A. L., da Silva, N. F., Tonchev, A., Chaldakov, G., James, S., et al. (2007). Adiponectin and resistin in human cerebrospinal fluid and expression of adiponectin receptors in the human hypothalamus. J. Clin. Endocrinol. Metab. 92, 1129-1136. doi: 10.1210/jc.2006-1841

Ksiezak-Reding, H., Pyo, H. K., Feinstein, B., and Pasinetti, G. M. (2003). Akt/PKB kinase phosphorylates separately Thr212 and Ser214 of tau protein in vitro. Biochim. Biophys. Acta 1639, 159-168. doi: 10.1016/j.bbadis.2003.09.001

Kullmann, S., Heni, M., Fritsche, A., and Preissl, H. (2015). Insulin action in the human brain: evidence from neuroimaging studies. J. Neuroendocrinol. 27, 419-423. doi: 10.1111/jne.12254

Lammie, G. A., Brannan, F., Slattery, J., and Warlow, C. (1997). Nonhypertensive cerebral small-vessel disease. An autopsy study. Stroke 28, 2222-2229. doi: 10.1161/01.str.28.11.2222

Landreth, G., Jiang, Q., Mandrekar, S., and Heneka, M. (2008). PPAR $\gamma$ agonists as therapeutics for the treatment of Alzheimer's disease. Neurotherapeutics 5, 481-489. doi: 10.1016/j.nurt.2008.05.003

Langa, K. M., Foster, N. L., and Larson, E. B. (2004). Mixed dementia: emerging concepts and therapeutic implications. JAMA 292, 2901-2908. doi: 10.1001/jama.292.23.2901

Langbaum, J. B., Chen, K., Lee, W., Reschke, C., Bandy, D., Fleisher, A. S., et al. (2009). Categorical and correlational analyses of baseline fluorodeoxyglucose positron emission tomography images from the Alzheimer's disease neuroimaging initiative (ADNI). Neuroimage 45, 1107-1116. doi: 10.1016/j. neuroimage.2008.12.072 
Le, D. S., Brookshire, T., Krakoff, J., and Bunt, J. C. (2009). Repeatability and reproducibility of the hyperinsulinemic-euglycemic clamp and the tracer dilution technique in a controlled inpatient setting. Metabolism 58, 304-310. doi: 10.1016/j.metabol.2008.09.029

Lebovitz, H. E. (2001). Insulin resistance: definition and consequences. Exp. Clin. Endocrinol. Diabetes 109, S135-S148. doi: 10.1055/s-2001-18576

Leney, S. E., and Tavaré, J. M. (2009). The molecular basis of insulin-stimulated glucose uptake: signalling, trafficking and potential drug targets. J. Endocrinol. 203, 1-18. doi: 10.1677/joe-09-0037

Lesort, M., and Johnson, G. V. (2000). Insulin-like growth factor-1 and insulin mediate transient site-selective increases in tau phosphorylation in primary cortical neurons. Neuroscience 99, 305-316. doi: 10.1016/s03064522(00)00200-1

Lesort, M., Jope, R. S., and Johnson, G. V. (1999). Insulin transiently increases tau phosphorylation: involvement of glycogen synthase kinase-3 $\beta$ and Fyn tyrosine kinase. J. Neurochem. 72, 576-584. doi: 10.1046/j.1471-4159.1999. 0720576.x

Leybaert, L., De Bock, M., Van Moorhem, M., Decrock, E., and De Vuyst, E. (2007). Neurobarrier coupling in the brain: adjusting glucose entry with demand. J. Neurosci. Res. 85, 3213-3220. doi: 10.1002/jnr.21189

Li, Y., Duffy, K. B., Ottinger, M. A., Ray, B., Bailey, J. A., Holloway, H. W., et al. (2010). GLP-1 receptor stimulation reduces amyloid- $\beta$ peptide accumulation and cytotoxicity in cellular and animal models of Alzheimer's disease. J. Alzheimers Dis. 19, 1205-1219. doi: 10.3233/jad-2010-1314

Li, Y., Perry, T., Kindy, M. S., Harvey, B. K., Tweedie, D., Holloway, H. W., et al. (2009). GLP-1 receptor stimulation preserves primary cortical and dopaminergic neurons in cellular and rodent models of stroke and Parkinsonism. Proc. Natl. Acad. Sci. U S A 106, 1285-1290. doi: 10.1073/pnas. 0806720106

Li, J. Q., Tan, L., Wang, H. F., Tan, M. S., Tan, L., Xu, W., et al. (2016). Risk factors for predicting progression from mild cognitive impairment to Alzheimer's disease: a systematic review and meta-analysis of cohort studies. J. Neurol. Neurosurg. Psychiatry 87, 476-484. doi: 10.1136/jnnp-2014-310095

Linder, K., Schleger, F., Ketterer, C., Fritsche, L., Kiefer-Schmidt, I., Hennige, A., et al. (2014). Maternal insulin sensitivity is associated with oral glucoseinduced changes in fetal brain activity. Diabetologia 57, 1192-1198. doi: 10.1007/s00125-014-3217-9

Llorens-Martín, M., Jurado, J., Hernández, F., and Avila, J. (2014). GSK3 $\beta$, a pivotal kinase in Alzheimer disease. Front. Mol. Neurosci. 7:46. doi: 10.3389/fnmol.2014.00046

Magistretti, P. J., and Pellerin, L. (1999). Astrocytes couple synaptic activity to glucose utilization in the brain. News Physiol. Sci. 14, 177-182.

Maher, F., Davies-Hill, T. M., Lysko, P. G., Henneberry, R. C., and Simpson, I. A. (1991). Expression of two glucose transporters, GLUT1 and GLUT3, in cultured cerebellar neurons: evidence for neuron-specific expression of GLUT3. Mol. Cell. Neurosci. 2, 351-360. doi: 10.1016/1044-7431(91)90066-w

Mamelak, M. (2012). Sporadic Alzheimer's disease: the starving brain. J. Alzheimers Dis. 31, 459-474. doi: 10.3233/JAD-2012-120370

Marks, J. L., King, M. G., and Baskin, D. G. (1991). Localization of insulin and type 1 IGF receptors in rat brain by in vitro autoradiography and in situ hybridization. Adv. Exp. Med. Biol. 293, 459-470. doi: 10.1007/978-1-46845949-4_41

Martin, B., Golden, E., Carlson, O. D., Pistell, P., Zhou, J., Kim, W., et al. (2009). Exendin- 4 improves glycemic control, ameliorates brain and pancreatic pathologies, and extends survival in a mouse model of Huntington's disease. Diabetes 58, 318-328. doi: 10.2337/db08-0799

Matthews, D. R., Hosker, J. P., Rudenski, A. S., Naylor, B. A., Treacher, D. F., and Turner, R. C. (1985). Homeostasis model assessment: insulin resistance and $\beta$ cell function from fasting plasma glucose and insulin concentrations in man. Diabetologia 28, 412-419. doi: 10.1007/bf00280883

McClean, P. L., Parthsarathy, V., Faivre, E., and Hölscher, C. (2011). The diabetes drug liraglutide prevents degenerative processes in a mouse model of Alzheimer's disease. J. Neurosci. 31, 6587-6594. doi: 10.1523/JNEUROSCI. 0529-11.2011

McNay, E. C., and Recknagel, A. K. (2011). Brain insulin signaling: a key component of cognitive processes and a potential basis for cognitive impairment in type 2 diabetes. Neurobiol. Learn. Mem. 96, 432-442. doi: 10.1016/j.nlm.2011.08.005
Mehran, A. E., Templeman, N. M., Brigidi, G. S., Lim, G. E., Chu, K. Y., Hu, X., et al. (2012). Hyperinsulinemia drives diet-induced obesity independently of brain insulin production. Cell Metab. 16, 723-737. doi: 10.1016/j.cmet.2012. 10.019

Meng, J. Z., Guo, L. W., Cheng, H., Chen, Y. J., Fang, L., Qi, M., et al. (2012). Correlation between cognitive function and the association fibers in patients with Alzheimer's disease using diffusion tensor imaging. J. Clin. Neurosci. 19, 1659-1663. doi: 10.1016/j.jocn.2011.12.031

Miller, B. W., Willett, K. C., and Desilets, A. R. (2011). Rosiglitazone and pioglitazone for the treatment of Alzheimer's disease. Ann. Pharmacother. 45, 1416-1424. doi: 10.1345/aph.1q238

Molinuevo, J. L., Ripolles, P., Simó, M., Lladó, A., Olives, J., Balasa, M., et al. (2014). White matter changes in preclinical Alzheimer's disease: a magnetic resonance imaging-diffusion tensor imaging study on cognitively normal older people with positive amyloid $\beta$ protein 42 levels. Neurobiol. Aging 35, 2671-2680. doi: 10.1016/j.neurobiolaging.2014.05.027

Moloney, A. M., Griffin, R. J., Timmons, S., O’Connor, R., Ravid, R., and O'Neill, C. (2010). Defects in IGF-1 receptor, insulin receptor and IRS-1/2 in Alzheimer's disease indicate possible resistance to IGF-1 and insulin signalling. Neurobiol. Aging 31, 224-243. doi: 10.1016/j.neurobiolaging.2008.04.002

Moreira, P. I., Duarte, A. I., Santos, M. S., Rego, A. C., and Oliveira, C. R. (2009). An integrative view of the role of oxidative stress, mitochondria and insulin in Alzheimer's disease. J. Alzheimers Dis. 16, 741-761. doi: 10.3233/jad-2009-0972

Morgello, S., Uson, R. R., Schwartz, E. J., and Haber, R. S. (1995). The human blood-brain barrier glucose transporter (GLUT1) is a glucose transporter of gray matter astrocytes. Glia 14, 43-54. doi: 10.1002/glia.440140107

Mullins, R. J., Mustapic, M., Goetzl, E. J., and Kapogiannis, D. (2017). Exosomal biomarkers of brain insulin resistance associated with regional atrophy in Alzheimer's disease. Hum. Brain Mapp. 38, 1933-1940. doi: 10.1002/hbm. 23494

Muniyappa, R., and Quon, M. J. (2007). Insulin action and insulin resistance in vascular endothelium. Curr. Opin. Clin. Nutr. Metab. Care 10, 523-530. doi: 10.1097/MCO.0b013e32819f8ecd

Muniyappa, R., and Sowers, J. R. (2013). Role of insulin resistance in endothelial dysfunction. Rev. Endocr. Metab. Disord. 14, 5-12. doi: 10.1007/s11154-0129229-1

Musen, G., Jacobson, A. M., Bolo, N. R., Simonson, D. C., Shenton, M. E., McCartney, R. L., et al. (2012). Resting-state brain functional connectivity is altered in type 2 diabetes. Diabetes 61, 2375-2379. doi: 10.2337/db11-1669

Nakano, H. (2004). Signaling crosstalk between NF-kappaB and JNK. Trends Immunol. 25, 402-405. doi: 10.1016/j.it.2004.05.007

Ott, A., Stolk, R. P., van Harskamp, F., Pols, H. A., Hofman, A., and Breteler, M. M. (1999). Diabetes mellitus and the risk of dementia: the rotterdam study. Neurology 53, 1937-1942. doi: 10.1212/WNL.53.9.1937

Papon, M. A., El Khoury, N. B., Marcouiller, F., Julien, C., Morin, F., Bretteville, A., et al. (2013). Deregulation of protein phosphatase 2A and hyperphosphorylation of tau protein following onset of diabetes in NOD mice. Diabetes 62, 609-617. doi: 10.2337/db12-0187

Pardridge, W. M., Eisenberg, J., and Yang, J. (1985). Human blood-brain barrier insulin receptor. J. Neurochem. 44, 1771-1778. doi: 10.1111/j.1471-4159.1985. tb07167.x

Pearson, H. A., and Peers, C. (2006). Physiological roles for amyloid $\beta$ peptides. J. Physiol. 575, 5-10. doi: 10.1113/jphysiol.2006.111203

Perez-Gonzalez, R., Gauthier, S. A., Kumar, A., and Levy, E. (2012). The exosome secretory pathway transports amyloid precursor protein carboxyl-terminal fragments from the cell into the brain extracellular space. J. Biol. Chem. 287, 43108-43115. doi: 10.1074/jbc.M112.404467

Perry, T., Haughey, N. J., Mattson, M. P., Egan, J. M., and Greig, N. H. (2002). Protection and reversal of excitotoxic neuronal damage by glucagon-like peptide-1 and exendin-4. J. Pharmacol. Exp. Ther. 302, 881-888. doi: 10.1124/jpet.102.037481

Perry, T., Holloway, H. W., Weerasuriya, A., Mouton, P. R., Duffy, K., Mattison, J. A., et al. (2007). Evidence of GLP-1-mediated neuroprotection in an animal model of pyridoxine-induced peripheral sensory neuropathy. Exp. Neurol. 203, 293-301. doi: 10.1016/j.expneurol.2006.09.028

Pessin, J. E., and Saltiel, A. R. (2000). Signaling pathways in insulin action: molecular targets of insulin resistance. J. Clin. Invest. 106, 165-169. doi: $10.1172 /$ jci10582 
Phelps, M. E., and Barrio, J. R. (2010). Correlation of brain amyloid with "aerobic glycolysis": a question of assumptions? Proc. Natl. Acad. Sci. U S A 107, 17459-17460. doi: 10.1073/pnas.1012684107

Planel, E., Sun, X. Y., and Takashima, A. (2002). Role of GSK-3 $\beta$ in Alzheimer's disease pathology. Drug Dev. Res. 56, 491-510. doi: 10.1002/ddr.10100

Porter, W. D., Flatt, P. R., Hölscher, C., and Gault, V. A. (2013). Liraglutide improves hippocampal synaptic plasticity associated with increased expression of Mash1 in ob/ob mice. Int. J. Obes. 37, 678-684. doi: 10.1038/ijo. 2012.91

Prasad, S., Sajja, R. K., Naik, P., and Cucullo, L. (2014). Diabetes mellitus and blood-brain barrier dysfunction: an overview. J. Pharmacovigil. 2:125. doi: 10.4172/2329-6887.1000125

Qiu, W. Q., and Folstein, M. F. (2006). Insulin, insulin-degrading enzyme and amyloid- $\beta$ peptide in Alzheimer's disease: review and hypothesis. Neurobiol. Aging 27, 190-198. doi: 10.1016/j.neurobiolaging.2005.01.004

Quiñones, M. J., Hernandez-Pampaloni, M., Schelbert, H., Bulnes-Enriquez, I., Jimenez, X., Hernandez, G., et al. (2004). Coronary vasomotor abnormalities in insulin-resistant individuals. Ann. Intern. Med. 140, 700-708. doi: 10.7326/0003-4819-140-9-200405040-00009

Rajendran, L., Honsho, M., Zahn, T. R., Keller, P., Geiger, K. D., Verkade, P., et al. (2006). Alzheimer's disease $\beta$-amyloid peptides are released in association with exosomes. Proc. Natl. Acad. Sci. U S A 103, 11172-11177. doi: 10.1073/pnas. 0603838103

Rasgon, N. L., Kenna, H. A., Wroolie, T. E., Kelley, R., Silverman, D., Brooks, J., et al. (2011). Insulin resistance and hippocampal volume in women at risk for Alzheimer's disease. Neurobiol. Aging 32, 1942-1948. doi: 10.1016/j. neurobiolaging.2009.12.005

Rasgon, N. L., Kenna, H. A., Wroolie, T. E., Williams, K. E., DeMuth, B. N., and Silverman, D. H. (2014). Insulin resistance and medial prefrontal gyrus metabolism in women receiving hormone therapy. Psychiatry Res. 223, 28-36. doi: 10.1016/j.pscychresns.2014.04.004

Reijmer, Y. D., Brundel, M., de Bresser, J., Kappelle, L. J., Leemans, A., Biessels, G. J., et al. (2013). Microstructural white matter abnormalities and cognitive functioning in type 2 diabetes: a diffusion tensor imaging study. Diabetes Care 36, 137-144. doi: 10.2337/dc12-0493

Reitz, C., Tosto, G., Mayeux, R., Luchsinger, J. A., NIA-LOAD/NCRAD Family Study Group, and Alzheimer's Disease Neuroimaging Initiative. (2012). Genetic variants in the Fat and Obesity Associated (FTO) gene and risk of Alzheimer's disease. PLoS One 7:e50354. doi: 10.1371/journal.pone.0050354

Rundek, T., Gardener, H., Xu, Q., Goldberg, R. B., Wright, C. B., Boden-Albala, B., et al. (2010). Insulin resistance and risk of ischemic stroke among nondiabetic individuals from the northern Manhattan study. Arch. Neurol. 67, 1195-1200. doi: 10.1001/archneurol.2010.235

Ryu, J., Galan, A. K., Xin, X., Dong, F., Abdul-Ghani, M. A., Zhou, L., et al. (2014). APPL1 potentiates insulin sensitivity by facilitating the binding of IRS $1 / 2$ to the insulin receptor. Cell Rep. 7, 1227-1238. doi: 10.1016/j.celrep.2014.04.006

Saido, T., and Leissring, M. A. (2012). Proteolytic degradation of amyloid $\beta$-protein. Cold Spring Harb. Perspect. Med. 2:a006379. doi: 10.1101/cshperspect.a006379

Sarazin, M., Lagarde, J., and Bottlaender, M. (2016). Distinct tau PET imaging patterns in typical and atypical Alzheimer's disease. Brain 139, 1321-1324. doi: 10.1093/brain/aww041

Sarbassov, D. D., Guertin, D. A., Ali, S. M., and Sabatini, D. M. (2005). Phosphorylation and regulation of $\mathrm{Akt} / \mathrm{PKB}$ by the rictor-mTOR complex. Science 307, 1098-1101. doi: 10.1126/science.1106148

Schneider, J. A., Arvanitakis, Z., Bang, W., and Bennett, D. A. (2007). Mixed brain pathologies account for most dementia cases in community-dwelling older persons. Neurology 69, 2197-2204. doi: 10.1212/01.WNL.0000271090.28148.24

Schulte, R. F., and Boesiger, P. (2006). ProFit: two-dimensional prior-knowledge fitting of J-resolved spectra. NMR Biomed. 19, 255-263. doi: 10.1002/nbm.1026

Schwartz, M. W., Figlewicz, D. F., Kahn, S. E., Baskin, D. G., Greenwood, M. R., and Porte, D. Jr. (1990). Insulin binding to brain capillaries is reduced in genetically obese, hyperinsulinemic Zucker rats. Peptides 11, 467-472. doi: 10.1016/0196-9781(90)90044-6

Searcy, J. L., Phelps, J. T., Pancani, T., Kadish, I., Popovic, J., Anderson, K. L., et al. (2012). Long-term pioglitazone treatment improves learning and attenuates pathological markers in a mouse model of Alzheimer's disease. J. Alzheimers Dis. 30, 943-961. doi: 10.3233/JAD-2012-111661
Sears, B., and Perry, M. (2015). The role of fatty acids in insulin resistance. Lipids Health Dis. 14:121. doi: 10.1186/s12944-015-0123-1

Sharma, A. N., Elased, K. M., Garrett, T. L., and Lucot, J. B. (2010). Neurobehavioral deficits in db/db diabetic mice. Physiol. Behav. 101, 381-388. doi: 10.1016/j.physbeh.2010.07.002

Shen, Y., Fu, W. Y., Cheng, E. Y., Fu, A. K., and Ip, N. Y. (2013). Melanocortin4 receptor regulates hippocampal synaptic plasticity through a protein kinase A-dependent mechanism. J. Neurosci. 33, 464-472. doi: 10.1523/JNEUROSCI. 3282-12.2013

Simpson, I. A., Dwyer, D., Malide, D., Moley, K. H., Travis, A., and Vannucci, S. J. (2008). The facilitative glucose transporter GLUT3: 20 years of distinction. Am. J. Physiol. Endocrinol. Metab. 295, E242-E253. doi: 10.1152/ajpendo.90 388.2008

Singh, T. J. (1993). Insulin receptor serine kinase activation by casein kinase 2 and a membrane tyrosine kinase. Mol. Cell. Biochem. 121, 167-174. doi: $10.1007 /$ BF00925976

Starks, E. J., Patrick O'Grady, J., Hoscheidt, S. M., Racine, A. M., Carlsson, C. M., Zetterberg, H., et al. (2015). Insulin resistance is associated with higher cerebrospinal fluid tau levels in asymptomatic APOE\&4 carriers. J. Alzheimers Dis. 46, 525-533. doi: 10.3233/JAD-150072

Steen, E., Terry, B. M., Rivera, E. J., Cannon, J. L., Neely, T. R., Tavares, R., et al. (2005). Impaired insulin and insulin-like growth factor expression and signaling mechanisms in Alzheimer's disease-is this type 3 diabetes? J. Alzheimers Dis. 7, 63-80. doi: 10.3233/jad-2005-7107

Steinberg, H. O., Tarshoby, M., Monestel, R., Hook, G., Cronin, J., Johnson, A., et al. (1997). Elevated circulating free fatty acid levels impair endotheliumdependent vasodilation. J. Clin. Invest. 100, 1230-1239. doi: 10.1172/JCI 119636

Steinberg, J. D., and Velan, S. S. (2013). Measuring glucose concentrations in the rat brain using echo-time-averaged point resolved spectroscopy at 7 tesla. Magn. Reson. Med. 70, 301-308. doi: 10.1002/mrm.24493

Stuart, J. M., Segal, E., Koller, D., and Kim, S. K. (2003). A gene-coexpression network for global discovery of conserved genetic modules. Science 302, 249-255. doi: 10.1126/science. 1087447

Sunkin, S. M., Ng, L., Lau, C., Dolbeare, T., Gilbert, T. L., Thompson, C. L., et al. (2013). Allen Brain Atlas: an integrated spatio-temporal portal for exploring the central nervous system. Nucleic Acids Res. 41, D996-D1008. doi: $10.1093 /$ nar/gks1042

Talbot, K., and Wang, H. Y. (2014). The nature, significance and glucagon-like peptide-1 analog treatment of brain insulin resistance in Alzheimer's disease. Alzheimers Dement. 10, S12-S25. doi: 10.1016/j.jalz.2013.12.007

Talbot, K., Wang, H. Y., Kazi, H., Han, L. Y., Bakshi, K. P., Stucky, A., et al. (2012). Demonstrated brain insulin resistance in Alzheimer's disease patients is associated with IGF-1 resistance, IRS-1 dysregulation, and cognitive decline. J. Clin. Invest. 122, 1316-1338. doi: 10.1172/JCI59903

Tanti, J. F., Grémeaux, T., van Obberghen, E., and Le Marchand-Brustel, Y. (1994). Serine/threonine phosphorylation of insulin receptor substrate 1 modulates insulin receptor signaling. J. Biol. Chem. 269, 6051-6057.

Thal, D. R., and Vandenberghe, R. (2016). Monitoring the progression of Alzheimer's disease with tau-PET. Brain 139, 1318-1320. doi: 10.1093/brain/aww057

Thambisetty, M., Jeffrey Metter, E., Yang, A., Dolan, H., Marano, C., Zonderman, A. B., et al. (2013). Glucose intolerance, insulin resistance, and pathological features of Alzheimer disease in the Baltimore Longitudinal Study of Aging. JAMA Neurol. 70, 1167-1172. doi: 10.1001/jamaneurol.2013.284

Thomas, M. A., Hattori, N., Umeda, M., Sawada, T., and Naruse, S. (2003). Evaluation of two-dimensional L-COSY and JPRESS using a 3 T MRI scanner: from phantoms to human brain in vivo. NMR Biomed. 16, 245-251. doi: $10.1002 / \mathrm{nbm} .825$

Tschritter, O., Haupt, A., Preissl, H., Ketterer, C., Hennige, A. M., Sartorius, T., et al. (2011). An obesity risk SNP (rs17782313) near the MC4R Gene is associated with cerebrocortical insulin resistance in humans. J. Obes. 2011:283153. doi: 10.1155/2011/283153

Tweedie, D., Rachmany, L., Rubovitch, V., Lehrmann, E., Zhang, Y., Becker, K. G., et al. (2012). Exendin-4, a glucagon-like peptide-1 receptor agonist prevents mTBI-induced changes in hippocampus gene expression and memory deficits in mice. Exp. Neurol. 239C, 170-182. doi: 10.1016/j.expneurol.2012. 10.001 
Tzatsos, A. (2009). Raptor binds the SAIN (Shc and IRS-1 NPXY binding) domain of insulin receptor substrate-1 (IRS-1) and regulates the phosphorylation of IRS-1 at Ser-636/639 by mTOR. J. Biol. Chem. 284, 22525-22534. doi: $10.1074 /$ jbc.M109.027748

Umegaki, H. (2013). Insulin resistance in the brain: a new therapeutic target for Alzheimer's disease. J. Diabetes Investig. 4, 150-151. doi: 10.1111/jdi. 12027

Urayama, A., and Banks, W. A. (2008). Starvation and triglycerides reverse the obesity-induced impairment of insulin transport at the blood-brain barrier. Endocrinology 149, 3592-3597. doi: 10.1210/en.2008-0008

Vaishnavi, S. N., Vlassenko, A. G., Rundle, M. M., Snyder, A. Z., Mintun, M. A., and Raichle, M. E. (2010). Regional aerobic glycolysis in the human brain. Proc. Natl. Acad. Sci. U S A 107, 17757-17762. doi: 10.1073/pnas.1010459107

van der Heide, L. P., Ramakers, G. M., and Smidt, M. P. (2006). Insulin signaling in the central nervous system: learning to survive. Prog. Neurobiol. 79, 205-221. doi: 10.1016/j.pneurobio.2006.06.003

Vlassenko, A. G., Vaishnavi, S. N., Couture, L., Sacco, D., Shannon, B. J., Mach, R. H., et al. (2010). Spatial correlation between brain aerobic glycolysis and amyloid- $\beta$ (A $\beta$ ) deposition. Proc. Natl. Acad. Sci. U S A 107, 17763-17767. doi: 10.1073/pnas.1010461107

Vogelsberg-Ragaglia, V., Schuck, T., Trojanowski, J. Q., and Lee, V. M. (2001). PP2A mRNA expression is quantitatively decreased in Alzheimer's disease hippocampus. Exp Neurol 168, 402-412. doi: 10.1006/exnr.2001.7630

Wallum, B. J., Taborsky, G. J. Jr., Porte, D. Jr., Figlewicz, D. P., Jacobson, L., Beard, J. C., et al. (1987). Cerebrospinal fluid insulin levels increase during intravenous insulin infusions in man. J. Clin. Endocrinol. Metab. 64, 190-194. doi: 10.1210/jcem-64-1-190

Wang, D. S., Dickson, D. W., and Malter, J. S. (2006). $\beta$-Amyloid degradation and Alzheimer's disease. J. Biomed. Biotechnol. 2006:58406. doi: $10.1155 / \mathrm{JBB} / 2006 / 58406$

Watson, G. S., Peskind, E. R., Asthana, S., Purganan, K., Wait, C., Chapman, D., et al. (2003). Insulin increases CSF A 442 levels in normal older adults. Neurology 60, 1899-1903. doi: 10.1212/01.WNL.0000065916.25128.25

Welsh, G. I., and Proud, C. G. (1993). Glycogen synthase kinase-3 is rapidly inactivated in response to insulin and phosphorylates eukaryotic initiation factor eIF-2B. Biochem. J. 294, 625-629. doi: 10.1042/bj2940625

Weston, P. S., Simpson, I. J., Ryan, N. S., Ourselin, S., and Fox, N. C. (2015). Diffusion imaging changes in grey matter in Alzheimer's disease: a potential marker of early neurodegeneration. Alzheimers Res. Ther. 7:47. doi: 10.1186/s13195-015-0132-3

Willette, A. A., Bendlin, B. B., Starks, E. J., Birdsill, A. C., Johnson, S. C., Christian, B. T., et al. (2015a). Association of insulin resistance with cerebral glucose uptake in late middle-aged adults at risk for Alzheimer disease. JAMA Neurol. 72, 1013-1020. doi: 10.1001/jamaneurol.2015.0613

Willette, A. A., Johnson, S. C., Birdsill, A. C., Sager, M. A., Christian, B., Baker, L. D., et al. (2015b). Insulin resistance predicts brain amyloid deposition in late middle-aged adults. Alzheimers Dement. 11, 504.e1-510.e1. doi: 10.1016/j.jalz.2014.03.011
Willette, A. A., Modanlo, N., Kapogiannis, D., and Alzheimer's Disease Neuroimaging Initiative. (2015c). Insulin resistance predicts medial temporal hypermetabolism in mild cognitive impairment conversion to Alzheimer disease. Diabetes 64, 1933-1940. doi: 10.2337/db14-1507

Willette, A. A., Xu, G., Johnson, S. C., Birdsill, A. C., Jonaitis, E. M., Sager, M. A., et al. (2013). Insulin resistance, brain atrophy and cognitive performance in late middle-aged adults. Diabetes Care 36, 443-449. doi: 10.2337/dc12-0922

Woods, S. C., and Porte, D. Jr. (1977). Relationship between plasma and cerebrospinal fluid insulin levels of dogs. Am. J. Physiol. 233, E331-E334.

Xiong, Y., Sui, Y., Xu, Z., Zhang, Q., Karaman, M. M., Cai, K., et al. (2016). A diffusion tensor imaging study on white matter abnormalities in patients with type 2 diabetes using tract-based spatial statistics. AJNR Am. J. Neuroradiol. 37, 1462-1469. doi: 10.3174/ajnr.A4740

Xu, W., Yang, Y., Yuan, G., Zhu, W., Ma, D., and Hu, S. (2015). Exendin-4, a glucagon-like peptide-1 receptor agonist, reduces Alzheimer disease-associated tau hyperphosphorylation in the hippocampus of rats with type 2 diabetes. J. Investig. Med. 63, 267-272. doi: 10.1097/JIM.0000000000000129

Yamamoto, N., Matsubara, T., Sobue, K., Tanida, M., Kasahara, R., Naruse, K., et al. (2012). Brain insulin resistance accelerates $A \beta$ fibrillogenesis by inducing GM1 ganglioside clustering in the presynaptic membranes. J. Neurochem. 121, 619-628. doi: 10.1111/j.1471-4159.2012.07668.x

Yoon, S. O., Park, D. J., Ryu, J. C., Ozer, H. G., Tep, C., Shin, Y. J., et al. (2012). JNK3 perpetuates metabolic stress induced by A $\beta$ peptides. Neuron 75 , 824-837. doi: 10.1016/j.neuron.2012.06.024

Zeng, G., and Quon, M. J. (1996). Insulin-stimulated production of nitric oxide is inhibited by wortmannin. Direct measurement in vascular endothelial cells. J. Clin. Invest. 98, 894-898. doi: 10.1172/jci118871

Zhang, J., and Liu, F. (2014). Tissue-specific insulin signaling in the regulation of metabolism and aging. IUBMB Life 66, 485-495. doi: 10.1002/iub.1293

Zhao, W. Q., and Townsend, M. (2009). Insulin resistance and amyloidogenesis as common molecular foundation for type 2 diabetes and Alzheimer's disease. Biochim. Biophys. Acta 1792, 482-496. doi: 10.1016/j.bbadis.2008.10.014

Zhou, X. W., Winblad, B., Guan, Z., and Pei, J. J. (2009). Interactions between glycogen synthase kinase $3 \beta$, protein kinase $B$, and protein phosphatase $2 \mathrm{~A}$ in tau phosphorylation in mouse N2a neuroblastoma cells. J. Alzheimers Dis. 17, 929-937. doi: 10.3233/JAD-2009-1113

Conflict of Interest Statement: The authors declare that the research was conducted in the absence of any commercial or financial relationships that could be construed as a potential conflict of interest.

Copyright (® 2017 Mullins, Diehl, Chia and Kapogiannis. This is an open-access article distributed under the terms of the Creative Commons Attribution License (CC BY). The use, distribution or reproduction in other forums is permitted, provided the original author(s) or licensor are credited and that the original publication in this journal is cited, in accordance with accepted academic practice. No use, distribution or reproduction is permitted which does not comply with these terms. 